\title{
O EVENTO CARIRÍS VELHOS NA PROVÍNCIA BORBOREMA: INTEGRAÇÃO DE DADOS, IMPLICAÇÕES E PERSPECTIVAS
}

\author{
B. DE BRITO NEVES ${ }^{1}$, W. R. VAN SCHMUS ${ }^{2}$, E.J. DOS SANTOS $^{3}$, M. C. CAMPOS NETO ${ }^{1}$, M. KOZUCH ${ }^{2}$.
}

\begin{abstract}
RESUMO A Província Borborema sempre foi encarada como entidade do Ciclo Brasiliano, apesar da indefinição, em termos de datação, da idade de suas supracrustais no Proterozóico. O caráter de evolução policíclica foi usualmente admitido, baseado somente em dados $\mathrm{Rb}-\mathrm{Sr}$ e $\mathrm{K}-\mathrm{Ar}$, e alguns preconceitos. Este trabalho procura enfocar o impacto no conhecimento geológico regional causado pela introdução dos métodos $\mathrm{U}-\mathrm{Pb}$ e Sm-Nd nesta década, assim como procura ressaltar a coerência dos dados $\mathrm{Rb}-\mathrm{Sr}$ preexistentes (e mais alguns dados novos) com os dados obtidos com os métodos recém-introduzidos, mormente no trato com ortognaisses. Foi baseado em determinações Rb-Sr que a ocorrência de um Ciclo de Wilson pode ser agora primeiramente caracterizada nesta região, ao sul do Lineamento Patos. Tal ciclo, chamado "Cariris Velhos", agora com respaldo nos novos métodos de análise, mostra registros litogenéticos desde o Mesoproterozóico Superior (ca. 1100 Ma, abertura) até o início do Neoproterozóico (ca. 950 Ma, eventos colisionais tardios). A designação de Cariris Velhos corresponde a uma grande região geográfica natural do Nordeste, de há muito consagrada na fisiografia sertaneja, onde são notáveis os registros geológicos e geocronológicos deste ciclo então proposto. A sobreposição de eventos neoproterozóicos, plutônicos, vulcânicos e sedimentares é reconhecida por toda a Província, o que tem sido tem sido abrigado sob a égide do Ciclo Brasiliano (s.l.), e o que agora carece revisão e discriminação em etapas. A identificação deste ciclo tem implicações em diferentes níveis, regional, continental - possibilidades de correlação com "Occidentalia" e Sunsás-Aguapeí - assim como em termos da evolução mundial das massas continentais (Orogenia Grenville, Supercontinentes Rodínia, Pannotia e Gondwana). Estes fatos estão abrindo um leque amplo de questões para a geologia desta região e conseqüentemente de novas linhas de pesquisa.
\end{abstract}

\begin{abstract}
The Borborema Province had always been envisaged as a Brasiliano unit, and really it is it, in despite of the lack of data for the age of their supracrustal rocks. A polycyclical behavior of evolution hás always been admitted for this region, based only on $\mathrm{Rb}-\mathrm{Sr}$ and $\mathrm{K}-\mathrm{Ar}$ data. This paper is focussing the impact on the regional geological knowledge caused by the introduction during this decade of geochronological determinations with $\mathrm{U}-\mathrm{Pb}$ and $\mathrm{Sm}-\mathrm{Nd}$ methods, as well as it will emphasize the coherence of the obtained results with these methods and some preexisting $\mathrm{Rb}$-Sr ages (some new $\mathrm{Rb}-\mathrm{Sr}$ data will be added), specially on orthogneisses. It was based on $\mathrm{Rb}$-Sr data that the occurrence of an Wilson Cycle could firstly be pointed now out for this region, southwards of Patos lineament. This cycle, hencefórth being postulated and named as "Cariris Velhos" (name of a very large physiographic part of the Northeast, where these new data are conspícuos) displays lithogenetic records from the Late Mesoproterozoic (ca. $1100 \mathrm{Ma}$, rifting processes) up to the beginnings of the Neoproterozoic (ca. $950 \mathrm{Ma}$, late collisional events). Superposition of a complex orogenic history (post - 950Ma) is recognized ali over the province, to which the name of Brasiliano Cycle is usually attributed, what is now demanding be reviewed, as well as ali their steps have to be discriminated. The identification of Cariris Velhos Cycle brings strong implications to the regional knowledge, and to the continental evolution - possibilities of correlation with "Occidentalia" and Sunsás-Aguapeí, Mesoproterozoic terranes of the westem part of the continent. This is also true in terms of the worldwide evolution of the continental landmasses (Grenville orogeny, Rodinia, Pannotia and Gondwana supercontinents). Such facts, from now on, are opening an wide fan of questions and research lines for the Borborema Province.
\end{abstract}

INTRODUÇÃO O objetivo deste artigo é formalizar o conceito de Ciclo Cariris Velhos na Província Borborema, importante evento acrescionário e colisional na parte central desta província estrutural ("zona transversal" principalmente), registrado na passagem do Mesoproterozóico para o Neoproterozóico.

Embora os eventos já estivessem sendo percebidos com frequência desde o limiar desta década, e a designação já circulasse informalmente nos últimos três anos entre os geólogos militantes na região, este trabalho objetiva esta formalização, traçar um histórico e enfatizar as determinações $\mathrm{Rb}-\mathrm{Sr}$ preexistentes e (muitas) outras em andamento. As primeiras determinações U-Pb e Sm-Nd da Província Borborema confirmam plenamente este processo de interação notável de placas litosféricas, e serão consideradas devidamente, mas ficando claro que esta escala de abordagem é insuficiente, e requer muitos investimentos ainda, em termos de pesquisa e de tempo.

As determinações $\mathrm{Rb}$-Sr serão portanto enfocadas com primazia nesta oportunidade, em termos de apresentação de dados preexistentes, e dos dados obtidos nos últimos cinco anos, a fim de ser consignado uma espécie de depositário central para referências para o futuro e que possa nortear as pesquisas a advirem.

HISTÓRICO Desde a primeira síntese e reavalição dos dados geocronológicos da Borborema (Brito Neves et al. 1974) que afloraram as primeiras indicações (com K/Ar) sobre 
idades em torno de $1,0 \mathrm{Ga}$, que não foram sequer discutidos na oportunidade.

Em 1975, com novas determinações Rb-Sr e K-Ar, Brito Neves percebeu a existência de um evento em torno de 1,10 $\mathrm{Ga}( \pm 0,15)$, interpretando provisoriamente como uma "importante etapa de rejuvenescimento isotópico das rochas do embasamento" e provável etapa de instalação da "região geossinclinal". Em 1981, o mesmo autor enfocou a precariedade dos dados $\mathrm{Rb} / \mathrm{Sr}$ e $\mathrm{K} / \mathrm{Ar}$ (em termos de poder de resolução) para definir e discriminar eventos de diastrofísmo na Província, no que foi seguido por Santos \& Brito Neves (1984), devido as características geológicas naturais encontradas e diante da sobreposição forte dos processos ditos "brasilianos" (e/ou neoproterozóicos), reconhecendo assim a possibilidade de policiclismo.

Nesta época (anos 70 e 80) se tornou muito popular na província a ideia de uma história tectono-metamórfica prévia paleoproterozóica ou "transamazônica" (baseada numa interpretação pouco consistente de dados) para as supracrustais, e policiclismo inconteste (transamazônico + brasiliano), irradiada a partir de vários trabalhos de pesquisadores ligados ao Departamento de Geologia da UFRN, em Natal (vide histórico em Jardim de Sá 1994)

Em 1984, Brito Neves et al. trabalhando a parte geocronológica (Rb-Sr e K-Ar) do mapa 1/100 000 da folha de Salgueiro (em continuação ao levantamento feito por Sial et al. 1983) lograram obter valores próximos a $1,0 \mathrm{Ga}$, isócronas $\mathrm{Rb} / \mathrm{Sr}$, em dois contextos distintos. Primeiro, no embasamento do Maciço Pernambuco-Alagoas- PEAL (gnaisses e migmatitos do chamado "Complexo Cabrobó"), ao sul da área e, segundo, nas supracrustais e graníticas micáceas do sul de Salgueiro (rochas parcialmente migmatizadas e gnaissegranítico a moscovita) do chamado "Complexo SalgueiroCachoeirinha", do sistema de Dobramentos Piancó-Alto Brígida (SPAB). Diante de isócronas de muito boa qualificação em geral (que aqui vão ser reapresentadas, com modificações) e dos valores de idade inusitados, os autores interpretaram os resultados como resultado de um "Super Evento de Acresção e Diferenciação Continental" ou "SADC", inspirados na conceituação então vigente e em moda de Moorbarth (1975), mas deixando claro que estas poderiam ser idades mínimas (rejuvenescimento isotópico de rochas mais antigas). Ainda que de forma tímida, estes autores alegaram que estes valores de idades poderiam também representar a formação das rochas.

Lima et al. (1986), trabalhando no Sistema Pajeú-Paraiba (SPP) e no PEAL obtiveram vários resultados semelhantes ao de Brito Neves et al (1974), e que, cujos dados foram no presente trabalho rearranjados e serão reproduzidos. Cabe destacar uma isócrona de 1070 Ma para os gnaisses e migmatitos imediatamente ao norte de Belém do São Francisco ("Complexo Cabrobó"), e a isócrona de 1080 para rochas do mesmo contexto, pouco ao sul de Floresta. Ou seja, mostraram a persistência dos valores de 1,0 Ga na extensão para leste do Maciço PEAL, além de alguns outros valores pontuais de mesma idade nas litologias do SPP (rochas gnáissico-graníticas ao sul de Carqueja, hoje reconhecidas como da "Unidade Recanto", de Santos 1995). Mérito adicional destes autores foi reconhecer que estes valores de idades deveriam se referir aos tempos de formação das rochas, falando em termos de "Ciclo Uruaçuano" (designação naturalmente imprópria e ainda que com muita especulação envolvida) emprestado do centrooeste brasileiro, e indicando cartografícamente as áreas de provável incidência deste ciclo, dentro de um contexto amplo regional de policiclismo (Arqueano, "Transamazônico", "Uruaçuano", Brasiliano). Isto não pode ser comprovado em plenitude posteriormente, mas foi procedimento ousado e importante.

Em outras determinações de diversos trabalhos (de objetivos diversos) nesta província (mas não exclusivamente), a persistência de valores nessa ordem de idade foi um fato, por toda a década de 80 . De forma que, na edição do documento sobre a contribuição do Centro de Pesquisas Geocronológicas da USP para a subdivisão do Pré-Cambriano da América do Sul (Brito Neves et al 1990) um evento de 0,9 Ga foi colocado em evidência, tanto nos domínios Brasilianos como naqueles pré-Brasilianos (pós-Sunsás) do continente, ainda que sem uma interpretação definida, e longe até de quaisquer ilações interpretativas.

Na presente década, com o advento de determinações provenientes dos métodos $\mathrm{U}-\mathrm{Pb}$ e $\mathrm{Sm}-\mathrm{Nd}$, vários trabalhos foram desenvolvidos, com ratificação plena dos valores de idades no limite Meso-Neoproterozóico, nas mesmas litologias antes enfocadas e em novos contextos. Cabe destacar as sínteses de Van Schmus et al. (1995a e 1995b) que incorporaram vários Resumos e Resumos Expandidos até então publicados neste tema, a tese de doutoramento de Santos (1995) que detalha a área de Floresta-PE e o artigo de Campos Neto et al. (1994), onde a concepção (e até a designação) de um processo orogênico tomou vulto.

É necessário acrescentar que, neste mesmo período, em sua tese de doutoramento, Jardim de Sá (1994) e também Jardim de Sá et al. (1995), admite a hipótese de um processo colisional, no Meso-neoproterozóico, baseado nos dados geocronológicos e geoquímicos de alguns ortognaisses dos sistemas Riacho do Pontal - SRP e e Pajeú-Paraiba-SPP, revendo assim suas ideias anteriores de uma história "transamazônica" primordial nesta fração da província. Esta ideia de "transamazônico" generalizado havia marcado significativamente todos os textos, legendas e mapas $1 / 100.000$, do Projeto de Levantamentos Geológicos Básicos -PLGB- do sistema DNPM/ CPRM, para os quais Jardim de Sá atuara como consultor, e esta é uma assunção que deve ser agora criteriosamente revista. O "transamazônico" existe, é importante, é expressivo em área, mas pertence ao embasamento da província, antecedendo em muito a história meso-neoproterozóica de suas supracrustais.

No XVI Simpósio de Geologia do Nordeste, os trabalhos de Santos et al (1995), Van Schmus et al (1995b), Brito Neves et al.(1995) e Jardim de Sá (1995), dentre outros, a concepção de Orogenia Cariris Velhos foi amplamente discutida (ainda que nos termos e recursos de Resumos) e, ganhou substância. Este conceito deve ser compreendido como um processo wilsoniano de interação de placas litosféricas, com início em torno de 1,1 Ga (período Esteniano, com eventos preliminares conexos por todo o Mesoproterozóico) e fechamento no início do Neoproterozóico (período Toniano). Destes trabalhos parece claro (Brito Neves 1995) que este ciclo antecede francamente - e foi retomado por novos desenvolvimentos vulcano-sedimentares, magmáticos e tectogênicos do Neoproterozóico (Ciclo Brasiliano s.s.), desta feita extensivos (com ênfase para eventos de granitogênese e cisalhamento simples, mas não exlusivamente) para toda a Província. Não deve haver dúvidas que toda a estruturação geral da Província, sua "última forma" pré-deriva mesozóica, se deve aos eventos do Neoproterozóico (pós-950 Ma) ou do Bra- 
siliano, se esta designação for preferida para o conjunto de fenómenos envolvidos.

CONTEXTO GEOLÓGICO REGIONAL O acervo de publicações acerca da Província Borborema é bastante vasto, sendo aqui evocadas apenas as mais recentes. Para embasar quaisquer demandas complementares de informação sobre a província como um todo, devem ser destacadas as recentes teses de doutoramento de Jardim de Sá (1994) e Edilton Santos (1995), com excelentes coberturas sobre a região em apreço, inclusive com histórico de trabalhos prévios, e os de Van Schmus et al. (1995b) e Brito Neves et al. (1995), os dois últimos cobrindo mais aparte geocronológica. Do ponto de vista de cartografia geológica, devem ser mencionados, pela boa qualidade, os mais recentes mapas do PLGB, escala 1: 100.000 (alguns outros em escala 1: 250 000), do sistema DNPM/CPRM, e que tem servido como base (não-exclusiva) para as pesquisas geocronológicas.

Trata-se de uma ampla região de dobramentos do tipo branching system of orogens (Fig. 1), com supracrustais vulcano-sedimentares do Paleoproterozóico Tardio (e.g. OrósJaguaribe, sistema Jaguaribeano), Mesoproterozóico (grande maioria) e Neoproterozóico (ainda em fase de discriminação), arranjadas entre frações do embasamento ("terrenos", "maciços") e com estruturação final auferida ao final do Neoproterozóico III ao Cambriano (Ciclo Brasiliano), durante a articulação e fusão de Gondwana Ocidental. Sua configuração final, com linhas estruturais distribuídas em leque por todo o quadrante nordeste, foi só consignada nas últimas fases deformacionais, consorciada com o movimento direcional dos grandes lineamentos (Sobral/Transbrasiliano, Senador Pompeu, Patos, Pernambuco, etc.).

O embasamento da província parece ter sido majoritariamente consolidado no Paleoproterozóico (períodos Riaciano e Orosiriano), cujas faixas móveis aglutinam, circunscrevem e retrabalham os poucos núcleos arqueanos, cujos número e localização estão ainda em fase pesquisa e discriminação.

O contexto geológico-geográfico do evento orogênico Carirís Velhos está preferencialmente na parte central ("Zona Transversal") da Província, sistemas de dobramentos PiancóAlto Erigida (SPAB) e Pajeú-Paraiba (SPP), imediatamente ao sul do Lineamento de Patos. E ainda, há registros da continuidade de seus eventos na extensão sul do SPAB, no chamado Sistema de Dobramentos Riacho do Pontal (SRP) e na parte mais ocidental do Terreno/Maciço PernambucoAlagoas (PEAL), ou seja nas frações lito-estruturais contíguas a sul do Lineamento Pernambuco.

A norte do Lineamento de Patos, ratificando pois a importância do rejeito direcional nesta shear zone, a situação geológica muda bastante. Predomina um embasamento paleoproteozóico, circunscrevendo alguns núcleos arqueanos, e as faixa de supracrustais encontradas são de idades diferentes daquelas ao sul, respectivamente uma é paleoproterozóica (Sistema Jaguaribeano, mais a oeste) e outra parece ser Neo-

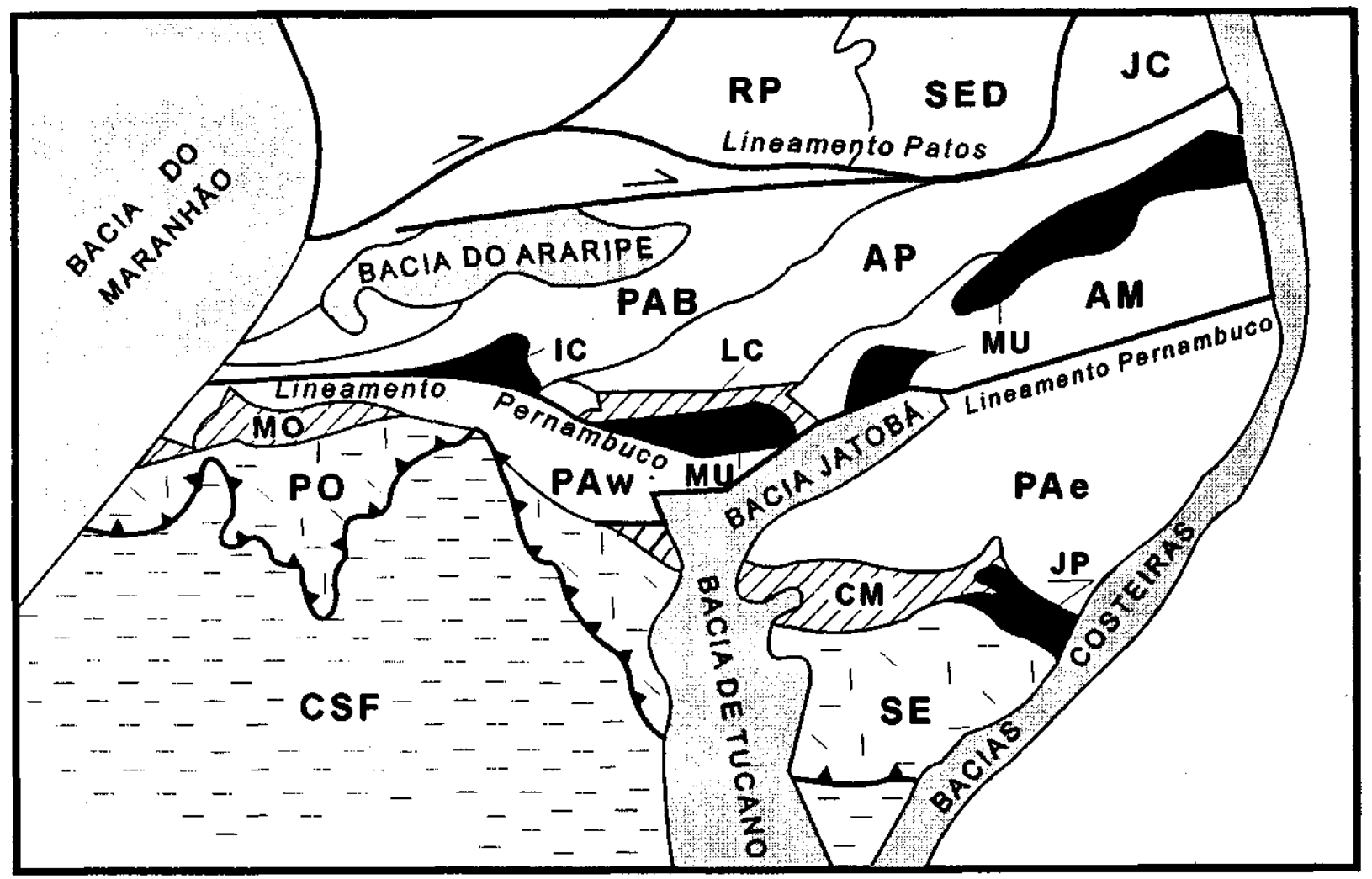

Figura J - Esboço geológico-geotectônico da Província Borborema, da zona transversal e imediações, salientando os principais terrenos/contextos lito-estruturais discutidos no texto.

$C S F=$ Cráton do São Francisco; PO - Riacho do Pontal; $M O=$ Monte Orebe; $I C=$ Icaiçara ; PAB = Piancó-Alto Erigida; $P A w$ e PAe = Maciço Pernambuco Alagoas, ocidental e oriental; $M u=$ Mulungu; $L C=$ Lagoa das Contendas; $A P=$ Alto Pajeú; AM = Alto Moxotó; $S E=$ Sistema Sergipano; $C M=$ Canindé; $J P=$ Jirau do Ponciano. $R P+S E D+J C=$ Maciços Rio Piranhas e Caldas Brandão e o Sistema Seridó entre eles, porção ao norte da Zona Transversal

Figure 1- General geologic-geographic sketch map for the Borborema Province, Northeast of Brazil, covering its "transversal central zone" and surroundings, with emphasis on the main terranes and litho-structural rock-units discussed in the text. 
proterozóica (Seridó), embora todos em conjunto tenham sido envolvidos nas orogenias do Brasiliano, no Neoproterozóico (granitogênese, trasncorrências e fenómenos conexos, intrusivas fissurais, pegmatitos, orientação geométrico-estrutural final, etc).

\section{Sistema Riacho do Pontal (SRP) Aspectos Geoló-} gicos No compartimento norte do SRP, entre o lineamento Pernambuco e a provável sutura de Monte Orebe, ocorrem exposições de rochas do embasamento (ortognáisses migmatizados de "Morro do Estreito"), retrabalhados policíclicamente e subjacente a uma sequência de turbiditos flischóides, com quartzitos, xistos bimicáceos bandados, intercalações de quartzitos e cálcio-silicáticas de ambiente marinho plataformal, abrigados sob a designação de Complexo Casa Nova (Angelim et al. 1988). Associados a este contexto ocorrem monzogranitos a granodioritos com biotita, textura augen, dentro do padrão regional de esforços tangenciais. Estas rochas são de natureza cálcio-alcalina e caráter peraluminoso (augen-gnaisse tipo "Afeição"), ocorrendo em forma de batólitos e stocks, e contém algumas inclusões de rochas encaixantes.

Há algumas evidências estruturais de que este compartimento mais ao norte seja um terreno mais antigo acrescido ao SRP, nos processos tectogênicos brasilianos, pois há indícios de estruturas mais antigas (indicadores cinemáticos para WS $\mathrm{W}$ e para $\mathrm{N}$, diferentes do restante da faixa móvel, conspicuamente vergente para sul e sudoeste), segundo Jardim de Sá (1994). Mas isto carece confirmação, inclusive com estudo mais detalhado da natureza dos xenólitos de supracrustais presentes nos gnaisses monzograníticos.

Dados Geocronológicos O batólito de Afeição (augengnaisse a biotita, monzogranítico a granodiorítico) a norte de Afrânio-PE, já no lado do Piaui, apresentou contexto interessante e coerente de dados geocronológicos, aqui reportado, a. Pelo método Rb-Sr foi obtida uma isócrona (Fig.2, Tabela 1) de $968 \pm 35 \mathrm{Ma}$, para Ro $=0,7037 \pm 0,00207(\mathrm{MSWD}=$ $1,8)$ para sete pontos analisados. Com seis pontos apenas, melhor alinhados a idade é de $938 \pm 35 \mathrm{Ma}$, sem modificações de vulto nos demais parâmetros, utilizando-se os dados analíticos de Jardim de Sá (1994) e do acervo do CpGeoUSP/ CPRM.

b. Pelo método do U-Pb em zircões, Jardim de Sá havia obtido um valor de idade de $986 \pm 48 \mathrm{Ma}$, que foi plenamente ratificado pelos presentes autores, em determinações separadas. Foi determinada uma idade de $966 \pm 10$ Ma (Tabela 7,
Fig. 3, amostra SRP-G-10), no intercepto superior de uma regressão de quatro pontos analíticos.

c. Pelo método $\mathrm{Pb} / \mathrm{Pb}$ em mono-zircão, Jardim de Sá (1994) reportou o valor de idade de $968 \pm 14 \mathrm{Ma}$.

d. Os dados Sm-Nd indicam Tdm = 1,46 Ga e End $_{600}=-3,4$

(Tabela 8), indicando formação mesoproterozóica provável para os protólitos e com franca residência crustal prévia, em plena coerência com os demais dados acima.

Estes valores tão concordantes sugerem a presença de um processo litogenético importante, provavelmente orogenético (colisional, pelo litotipo em discussão) nesta porção norte de SRP. As evidências de campo mostram que há franca continuidade desta porção de SRP para o bloco contíguo ao norte do Lineamento Pernambuco, domínio do SPAB, tendo em vista que são modestos os valores da transcorrência dextral neste trecho, como observado ao norte da cidade de Cruz de Malta-PE.

Se vier a ser comprovada a presença de xenólitos das meta-vulcânicas de Monte Orebe nestes corpos monzograníticos, é possível que toda esta faixa suturai (que apresenta assinatura geoquímica entre toleítos oceânicos e "arcos imaturos") seja do Eo-Neoproterozóica ou mais antiga, dando uma dimensão bem maior em área ao processo orogênico Cariris Velhos, aqui em discussão. A sobreposição de eventos

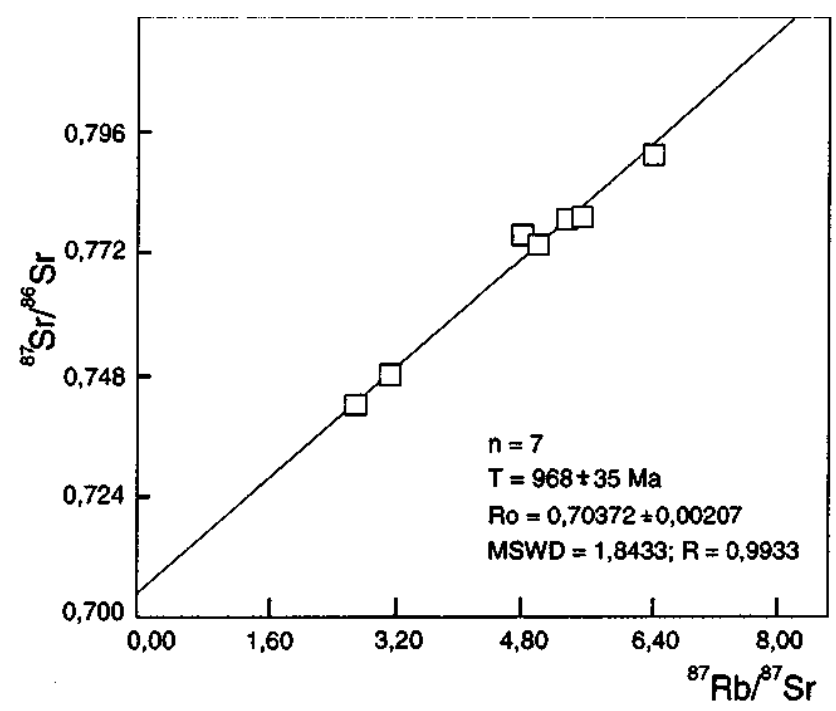

Figura 2 - Diagrama isocrônico para os ortognáisses de Afeição, ao norte de Afranio-PE (dados na Tabela 1).

Figure $2-\mathrm{Rb} / \mathrm{Sr}$ isochronic diagram for the orthogneisses of Afeição, north of Afranio-PE (analytical data Table 1).

Tabela J - Dados analiticos das determinações Rb/Sr no Augen-gnáisse (comp. monzonítica) de Afeição. Norte de Afrânio-PE Sistema Riacho do Pontal.

Table l - Analytical data for $\mathrm{Rb} / \mathrm{Sr}$ determinations on samples of the augen-gneiss of Afeição, north of Afranio-PE, Riacho do Pontal fold system (SPAB).

\begin{tabular}{|c|c|c|c|c|c|c|c|c|}
\hline SPR & $\mathrm{N}^{\circ}$ Campo & Rocha & Material & $\mathbf{R b}(\mathbf{p p m})$ & Sr (ppm) & $\mathrm{Rb}^{87} / \mathrm{Sr}^{86}$ & $\mathrm{Sr}^{87} / \mathrm{Sr}^{86}$ & Obs. \\
\hline 8862 & RP-2A & Monzogr. gnáisse & R.T. & 182,8 & 98,8 & $5,3860 \pm 0,1510$ & $0,777930 \pm 0,000020$ & $*$ \\
\hline 8863 & RP-2D & 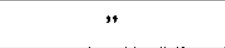 & $"$ & 179,4 & 103,3 & $5,1590 \pm 0,1420$ & $0,774080 \pm 0,000020$ & \\
\hline 8864 & RP-2E & $"$ & $"$ & 181,5 & 108,5 & $4,8740 \pm 0,1370$ & $0,775540 \pm 0,000040$ & \\
\hline 8865 & RP-2M & $"$ & $"$ & 246,6 & 110,6 & $6,5050 \pm 0,1820$ & $0,789610 \pm 0,000030$ & \\
\hline 9172 & LA-244C & $"$ & $"$ & 144,6 & 135,4 & $3,1030 \pm 0,0870$ & $0,747280 \pm 0,000190$ & \\
\hline 9173 & LA-244E & $"$ & $"$ & 127,6 & 131,9 & $2,8090 \pm 0,0790$ & $0,741840 \pm 0,000060$ & \\
\hline 9174 & LA $-409 \mathrm{C}$ & $"$ & $n$ & 186,8 & 100,0 & $5,444 \pm 0,1530$ & $0,777670 \pm 0,000080$ & \\
\hline
\end{tabular}

Obs: * Originais de Jardim de Sá et al. 1994; modificado. 
magmáticos e tectônicos neoproterozóicos (670 a 540 Ma) é fartamente documentada por todo restante do SRP (vide Santos \& Brito Neves 1984, Jardim de Sá 1994, dentre outros), desta porção norte até seu limite colisional sul na periferia setentrional e mesmo no interior do Cráton do São Francisco. De forma que o estudo geocronológico dos "complexos" Casa Nova e Monte Orebe parecem compromissos cruciais e inadiáveis, havendo a possibilidade de que este último venha a constituir resquícios (direta ou indiretamente) de oceanos mesoproterozóicos, a semelhança com a unidade "Pedras Pretas" no Sistema Pajeú-Paraiba (SPP), descrita por Santos (1995).

Por enquanto e por precaução, só o segmento norte do SRP está sendo arrolado como fração tectogênica (sobre embasamento paleoproterozóico) do Meso-neoproterozócio, ou seja do Ciclo Cariris Velhos.

SISTEMA PIANCÓ-ALTO BRÍGIDA-SPAB Conceito e Contexto lito-estratigráfico $\mathrm{O}$ SPAB se dispõe do alto curso do Rio da Farinha (na Paraíba), para oeste, com forma final (pós-tectogênese) triangular, tendo o Lineamento Patos por "limite" norte e o "alto Teixeira-Terra Nova" (a ser discutido) como virtual limite sul, cabendo registrar que através deste limite sul há pontos claros de prévia intercomunicação paleogeográfíca com o SPP. Trata-se de uma área clássica de sequências vulcano-sedimentares de baixo grau (tipos BVAC e QPC, de Condie 1989), e berço das localidades-tipo dos granitos "brasilianos" ou neoproterozóicos ("Conceição", "Itaporanga" e "Catingueira") da Borborema, cuja bibliografia remonta à década de 60 , e é vastíssima.

As mais atualizadas abordagens e sínteses sobre este sistema podem ser vistas no "Projeto Cachoeirinha" (1985) e nos mapas do PLGB (folhas Patos, Afogados de Ingazeira, etc.), todos do sistema DNPM-CPRM. Trabalhos mais recentes, de Campos Neto et al. (1994) consideram os anteriormente citados, e trazem uma concepção moderna para o entendimento deste sistema (estratigrafia, tectônica), o que vem sendo complementado por diversos pesquisadores da UFPE, em termos de geoquímica das vulcânicas (Lima et al. 1996), e outros detalhes.

São reconhecidos três contextos litoestratigráficos informais na parte mediana do sistema, que estão ordenados de sul para norte, e que registram os passos sucessivos de evolução de SPAB, a saber:

a. Unidade Vulcano-Sedimentar Riacho Gravata - Neste contexto, dois conjuntos litológicos foram reconhecidos, preservados como lascas de cavalgamento em dois níveis estruturais diferentes, metamorfizados em grau médio(ao sul) a fraco (norte), no perfil de Manaira -Santana das Mangueiras.

O primeiro conjunto é de natureza meta-pelítico e metatufáceo, com intercalações de metaritmitos pelítico-psamíticos. Ocorrem intercaladas metavulcânicas félsicas e metavulcânicas ácidas (ortognaisses). O segundo conjunto é composto por metagrauvacas vulcanoclásticas (magnetita-granada xistos), calcífera em direção a base, onde aparecem expressivas lentes de mármore, grafita-xisto e tremolita-actinolita xisto e quartzitos.

O magmatismo desta unidade é indicativo de regime distensional intraplaca, provavelmente do estágio rifte precursor do desenvolvimento do sistema. Pelas determinações geocronológicas (Brito Neves et al. 1990), estes eventos remontam a $1100 \mathrm{Ma}$, como será comentado. b. Unidade Vulcano-sedimentar de Poço dos Cachorros Nesta unidade predominam xistos esverdeados manganesíferos, a biotita, clorita e anfibólio, com intercalações de actinolita-xistos e clorita-xistos diversos. Filitos grafitosos e quartzitos ferríferos bandados ocorrem subsidiariamente. $\mathrm{O}$ vulcanismo é de natureza básico-inermediário, com ocorrências de basaltos, basaltos andesíticos e andesitos. O quimismo destas rochas é indicativo com posição em bacias extensionais submarinas (tipos similares a MORB presentes), segundo Lima et al (1996). Os contatos desta unidades com as que a encaixam são por falhamentos, e com relação a unidade de topo, há notável queda no grau metamórfico. c. Unidade Metaturbidítica da Serra Olho d'-Água - Nesta unidade se destacam dois conjuntos distintos: um inferior, de ambiente de plataforma continental de relevo irregular e escalonado (ca. $1100 \mathrm{~m}$ ) e uma de leques marinhos profundos. $\mathrm{Na}$ unidade basal predominam sequências turbidíticas arenoargilosas com completos, e estruturas do tipo corte-e-preenchimento e wave-ripples sobrepostos por meta-ritmitos, níveis pelíticos e níveis psamo-pelítiticos, com intercalações de cálcio-silicáticas e quartzitos. No contexto mais profundo, na base predominam meta-conglomerados polimícticos mal selecionados, com blocos arredondados e sub-esféricos e granodecrescência marcante (compostos por quartzitos, metavulcânicas, granitos, mármore, etc.) imersos numa matriz microconglomerática. Mais para o topo aparecem unidades psamo-pelíticas, com meta-arenitos finos a muito finos, onde também se verificam granodecrescência e intercalações de dacíticas e de vulcânicas ácidas. Os dados estratigráficos e os dados geoquímicos (muito preliminares) desta unidade são indicativos de ambiente submarino. Há uma possibilidade deste conjunto pertencer a história neoproterozóica de SPAB, consoante alguns dados de campo, faltando a comprovação geocronológica.

Pouco ao norte do paralelo de Santana dos Garrotes, e daí até Piancó-PB, norte destas unidades ocorre uma nappe voltada para nordeste, de xistos a biotita e sillimanitata, com muitas venulações migmatíticas ("nappe de Piancó"), cuja vinculação com as sequências antes descritas é questão em aberto (metamorfísmo, estratigrafia, etc.)

Dados Geocronológicos Região Sul de Salgueiro-PE Ao sul de Salgueiro-PE, na área entre as localidades de Vassouras e Murici, tendo por base o mapa geológico 1/100.000, realizado por professores e alunos da UFPE (relatados em Sial et al 1983), foram coietadas amostras das rochas do "Grupo Cachoeirinha-Salgueiro" (designação então comprovada como imprópria), ou Unidade C, consoante designação informal adotada. Tratavam-se de ortognaisses a duas micas ("Gnaisse da Serra das Vassouras"), discretamente bandado e sua versão migmatítica ("augen-gnaisses, diatexitos) da sinforme de Murici.

Estas rochas das série DBSA-C e DBSA-B (Tabela 2, Fig. 4) forneceram uma isócrona de $\mathrm{T}=937 \pm 14 \mathrm{Ma}, \mathrm{Ro}=0,707$ $\pm 0,00089$ (MSWD $=5,3$ ) para onze diferentes pontos analisados, numa revisão e atualização da isócrona dantes apresentada por Brito Neves et al (1984). Já naquela oportunidade foi levantada a observação da semelhança deste resultado com aqueles que foram encontrados mais ao sul, no domínio do PEAL (a serem comentados), nas imediações de Cabrobó.

As rochas gnáissicas da Serra das Vassouras (Amostra SPAB-G-1) tiveram este valor de idade confirmado pela determinação U-Pb em zircão de T=999 \pm 50 Ma (Fig. 3, Tabela 
Tabela 2 - Dados analiticos das determinações Rb/Sr - Sistema Piancó-Alto Brígida, ao sul de Salgueiro PE. Table 2 - Analytical data for the Rb/Sr determinations - Piancó - Alto Brígida fold system, area south of Salgueiro-PE.

\begin{tabular}{|c|c|c|c|c|c|c|c|c|c|c|}
\hline SPR & $\mathrm{N}^{\circ}$ Campo & Rocha & Material & $\mathbf{R b}(\mathrm{ppm})$ & Sr (ppm) & $\mathrm{Rb}^{87} / \mathrm{Sr}^{86}$ & $\mathrm{Sr}^{87} / \mathrm{Sr}^{86}$ & \multicolumn{2}{|c|}{ Coordenadas } & Obs. \\
\hline 6597 & DBSB-40 & Bio-gnaisse & R.T. & 252.2 & 97.2 & $7,55 \pm 0,211$ & $0,8216 \pm 0,0009$ & $8^{\circ} 25^{\prime} 00^{\prime \prime} \mathrm{s}$ & $39^{\circ} 06^{\prime} 10^{\prime}, \mathrm{W}$ & $*$ \\
\hline 6677 & DBSB-41 & Bio-gnaisse & $"$ & 236.1 & 119.4 & $5,77 \pm 0,162$ & $0,7872 \pm 0,0005$ & $8^{\circ} 20^{\prime} 20^{\prime \prime} \mathrm{S}$ & $39^{\circ} 10^{\prime} 00^{\prime \prime} \mathrm{W}$ & ** \\
\hline 6678 & DBSB-42 & Bio-gnaisse & $"$ & 50.0 & 1.3 & $10,28 \pm 0,287$ & $0,9361 \pm 0,0003$ & $8^{\circ} 20^{\prime} 10^{\prime \prime} \mathrm{S}$ & $39^{\circ} 13^{\prime} 35^{\prime} \mathrm{W}$ & \\
\hline 6679 & DBSB-48 & Bio-gnaisse & $"$ & 277.0 & 87.1 & $9,32 \pm 0,260$ & $0,9305 \pm 0,0003$ & $8^{\circ} 20^{\prime} 10^{\prime \prime} \mathrm{S}$ & $39^{\circ} 13^{\prime} 35^{\prime \prime} \mathrm{W}$ & \\
\hline 6858 & DBSC-51 & Bio-Musc-gnaisse & $"$ & 240.3 & 104.3 & $6,73 \pm 0,19$ & $0,901501 \pm 0,000129$ & $8^{\circ} 18^{\prime} 35^{\prime \prime} \mathrm{S}$ & $39^{\circ} 04^{\prime} 30^{\prime \prime} \mathrm{W}$ & \\
\hline 6859 & DBSC-52 & Augen-gnaisse & $"$ & 3.1 & 2.6 & $9,75 \pm 0,27$ & $0,841490 \pm 0,000082$ & $8^{\circ} 16^{\prime} 25^{\prime \prime} \mathrm{s}$ & $39^{\circ} 18^{\prime} 20^{\prime \prime} \mathrm{W}$ & \\
\hline 6860 & DBSC-53 & Bio-gnaisse & $"$ & 134.1 & 291.1 & $1,33 \pm 0,04$ & $0,7269941 \pm 0,00079$ & $8^{\circ} 14^{\prime} 30^{\prime \prime} \mathrm{S}$ & $39^{\circ} 29^{\prime} 35^{\prime \prime} \mathrm{W}$ & \\
\hline 6863 & DBSC-56 & Gnaisse xistoso & $"$ & 109.7 & 621.1 & $0,51 \pm 0,02$ & $0,716393 \pm 0,000056$ & $8^{\circ} 14^{\prime} 00^{\prime \prime} \mathrm{S}$ & $39^{\circ} 28^{\prime} 40^{\prime} \mathrm{W}$ & \\
\hline 6884 & DBSC- 60 & Bio-gnaisse & $"$ & 360.4 & 9.8 & $1,80 \pm 33$ & $0,875065 \pm 0,000096$ & $8^{\circ} 17^{\prime} 40^{\prime \prime} \mathrm{S}$ & $39^{\circ} 10^{\prime} 40^{\prime} \mathrm{W}$ & \\
\hline 7028 & DBSC-62 & Migmatito & $"$ & 205.4 & 258.2 & $2,31 \pm 0,07$ & $0,735499 \pm 0,0000544$ & $8^{\circ} 20^{\prime} 20^{\prime \prime} \mathrm{S}$ & $39^{\circ} 06^{\prime} 30^{\prime \prime} \mathrm{W}$ & \\
\hline 7029 & DBSC-64 & Gnaisse & $"$ & 252.1 & 86.3 & $8,20 \pm 0,23$ & $0,816605 \pm 0,001162$ & $8^{\circ} 18^{\prime} 09^{\prime \prime S}$ & $39^{\circ} 10^{\prime} 58^{\prime \prime} \mathrm{W}$ & \\
\hline 7030 & DBSC- 66 & Gnaisse migmat. & $"$ & 208.5 & 63.3 & $9,64 \pm 0,27$ & $0,821302 \pm 0,000150$ & $8^{\circ} 15^{\prime} 30^{\prime \prime} \mathrm{S}$ & $39^{\circ} 05^{\prime} 40^{\prime \prime} \mathrm{W}$ & ** \\
\hline 7031 & DBSC-67 & Musc-Qzo-xisto & $"$ & 189.5 & 77.2 & $7,16 \pm 0,20$ & $0,791770 \pm 0,000512$ & $8^{\circ} 15^{\prime} 30^{\prime \prime} \mathrm{S}$ & $39^{\circ} 05^{\prime} 40^{\prime \prime} \mathrm{W}$ & $* *$ \\
\hline
\end{tabular}

Obs: * Dados originais de Brito Neves et al. 1984; re-ordenados.

** Não incluídos na isócrona da Figura 2.

Tabela 3 - Dados analíticos das determinações Rb/Sr no Sistema Piancó-Alto Brígida, Riacho Gravata e adjacências - PB.

Table 3 - - Analytical data for $\mathrm{Rb} / \mathrm{Sr}$ determinations on rocks along the Gravatá Creek (felsic meta-volcanic, schists)- Piancó -Alto Brígida fold system.

\begin{tabular}{|c|c|c|c|c|c|c|c|c|c|c|}
\hline SPR & $\mathbf{N}^{0}$ Campo & Rocha & Material & $\underset{(\mathbf{p p m})}{\mathbf{R b}}$ & $\underset{(\mathbf{p p m})}{\mathbf{S r}}$ & $\mathrm{Rb}^{87} / \mathrm{Sr}^{86}$ & $S r^{87} / S^{86}$ & \multicolumn{2}{|c|}{ Coordenadas } & Obs. \\
\hline 12946 & SPAB-V-60z & Meta-riolito & R.T. & 329,6 & 35,4 & $27,98 \pm 0,7620$ & $1,096880 \pm 0,000170$ & $7^{\circ} 36^{\prime} 04^{\prime \prime} \mathrm{s}$ & $38^{\circ} 02^{\prime} 30^{\prime \prime} \mathrm{W}$ & * \\
\hline 9087 & SPAB-V-2 & Meta-riolito & $"$ & 309,2 & 47,8 & $19,199 \pm 0,530$ & $0,976590 \pm 0,000060$ & $7^{\circ} 36^{\prime} 04^{\prime \prime} \mathrm{S}$ & $38^{\circ} 02^{\prime} 30^{\prime \prime} \mathrm{W}$ & $*$ \\
\hline 9088 & SPAB-V-4 & Meta-riolito & 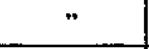 & 268,55 & 52,0 & $15,258 \pm 0,4230$ & $0,930740 \pm 0,000070$ & $7^{\circ} 36^{\prime} 04^{\prime \prime} \mathrm{S}$ & $38^{\circ} 02^{\prime} 30^{\prime \prime} \mathrm{W}$ & * \\
\hline 9089 & SPAB-V-8 & Meta-riolito & $"$ & 290,4 & 56,5 & $15,2040 \pm 0,4210$ & $0,941349 \pm 0,000060$ & $7^{\circ} 36^{\prime} 04^{\prime \prime} \mathrm{S}$ & $38^{\circ} 02^{\prime} 30^{\prime \prime} \mathrm{W}$ & $*$ \\
\hline 9340 & SPAB-V-60C & Meta-riolito & , & 229,7 & 92,7 & 2030 & $0,817240 \pm 0,000140$ & $7^{\circ} 36^{\prime} 04^{\prime \prime} \mathrm{S}$ & $38^{\circ} 02^{\prime} 30^{\prime \prime} \mathrm{W}$ & $*$ \\
\hline 9277 & SPAB-V-60D & Meta-riolito & $"$ & 237.0 & 93,5 & $9,4900 \pm 0,2640$ & $0,879470 \pm 0,00080$ & $7^{\circ} 36^{\prime} 04^{\prime \prime} \mathrm{s}$ & $38^{\circ} 02^{\prime} 30^{\prime \prime} \mathrm{W}$ & * \\
\hline 9341 & SPAB-V-60E & Meta-riolito & $"$ & 339,6 & 36,18 & $28,07 \pm 0,2800$ & $1,04424 \pm 0,00028$ & $7^{\circ} 36^{\prime} 04^{\prime \prime} \mathrm{s}$ & $38^{\circ} 02^{\prime} 30^{\prime \prime} \mathrm{W}$ & $*$ \\
\hline 9078 & SPAB-V-60G & Meta-riolito & $*$ & 349,37 & 31,83 & $33,13 \pm 0,3513$ & $1,14880 \pm 0,00150$ & $7^{\circ} 36^{\prime} 04^{\prime \prime} \mathrm{S}$ & $38^{\circ} 02^{\prime} 30^{\prime \prime} \mathrm{W}$ & $*$ \\
\hline 9342 & SPAB-V-60I & Meta-riolito & " & 313,67 & 46,75 & $19,9037 \pm 0,1336$ & $0,96302 \pm 0,001880$ & $7^{\circ} 36^{\prime} 04^{\prime \prime} \mathrm{S}$ & $38^{\circ} 02^{\prime \prime} 30^{\prime \prime} \mathrm{W}$ & $*$ \\
\hline 9278 & SPAB-60A & Xisto Biotítico & $"$ & 96,60 & 230,60 & $1,2100 \pm 0,030$ & $0,727320 \pm 0,000060$ & $7^{\circ} 36^{\prime} 04^{\prime \prime} \mathrm{S}$ & $38^{\circ} 02^{\prime} 30^{\prime \prime} \mathrm{W}$ & $* *$ \\
\hline 4343 & SPAB-70A & Xisto Biotítico & $"$ & 108,4 & 249,50 & $1,2600 \pm 0,030$ & $0.757960 \pm 0,000050$ & $7^{\circ} 36^{\prime} 04^{\prime \prime} \mathrm{s}$ & $38^{\circ} 13^{\prime} 34^{\prime \prime} \mathrm{W}$ & $* * *$ \\
\hline 9344 & SPAB-70B & Xisto Biotítico & "s & 224,8 & 93,00 & $7,0400 \pm 0,200$ & $0,778570 \pm 0,000030$ & $7^{\circ} 39^{\prime} 21^{\prime \prime} \mathrm{S}$ & $38^{\circ} 13^{\prime} 34^{\prime \prime} \mathrm{W}$ & $* * *$ \\
\hline 9345 & PAB-75 & Meta-ritmitos & $"$ & 105,0 & 98,50 & $3,0900 \pm 0,090$ & $0,735360 \pm 0,000040$ & $7^{\circ} 39^{\prime} 21^{\prime \prime} \mathrm{S}$ & $38^{\circ} 15^{\prime} 00^{\prime \prime} \mathrm{W}$ & $* * *$ \\
\hline
\end{tabular}

Obs: * Originais em Brito Neves et al. 1990; com modificações e adendo. Unidade Riacho Gravatá

** Encaixante da vulcânica do Riacho Gravatá

*** Outras litologias, distais das vulcânicas

7). Amostras do mesmo contexto apresentaram valores de idade $\mathrm{Tdm}=1>97$ e 1,68, para valores ENdeoo $=-4,9$ e - 4,6, respectivamente (Tabela 8), o que de certa forma é semelhante com resultados (e significados) encontrados para a amostra SRP-G-10, em Afeição.

Região norte de Manaira- $P B$ As rochas meta-vulcânicas ácidas (meta-riolitos, com muscovita e biotita) da Unidade Riacho Gravata, no trecho conhecido como Riacho Piaus, ao norte de Manaira-PB (Série SPAB-V, Tabela 3, Fig. 5), bem como algumas de suas encaixantes xistosas produziram uma isócrona $\mathrm{Rb}$-Sr de $\mathrm{T}=948 \pm 6$ Ma para $\mathrm{Ro}=0,7113 \pm 0,00050$, em um diagrama onde é forte a dispersão (MSWD $=29,6 \mathrm{e}$ coeficiente de correlação $\mathrm{R}=0,997$ ), numa revisão e ampliação dos dados de Brito Neves et al. (1990). Apesar da qualificação precária do diagrama de regressão (esperável, posto que inclui xistos de encaixantes), é preciso acrescentar as características de diversidade do amplo afloramento de coleta (ao longo do riacho), onde foram propositadamente procurados ao máximo litologias macroscopicamente distintas que pudessem conceder um bom espraiamento da razão $\mathrm{Rb}$-Sr. De rochas deste afloramento (SPAB-V-60) foi obtida um concórdia U-Pb com intercepto superior de $\mathrm{T}=1070 \pm 30$ $\mathrm{Ma}$, e de outro afloramento da mesma unidade litoestrati- 


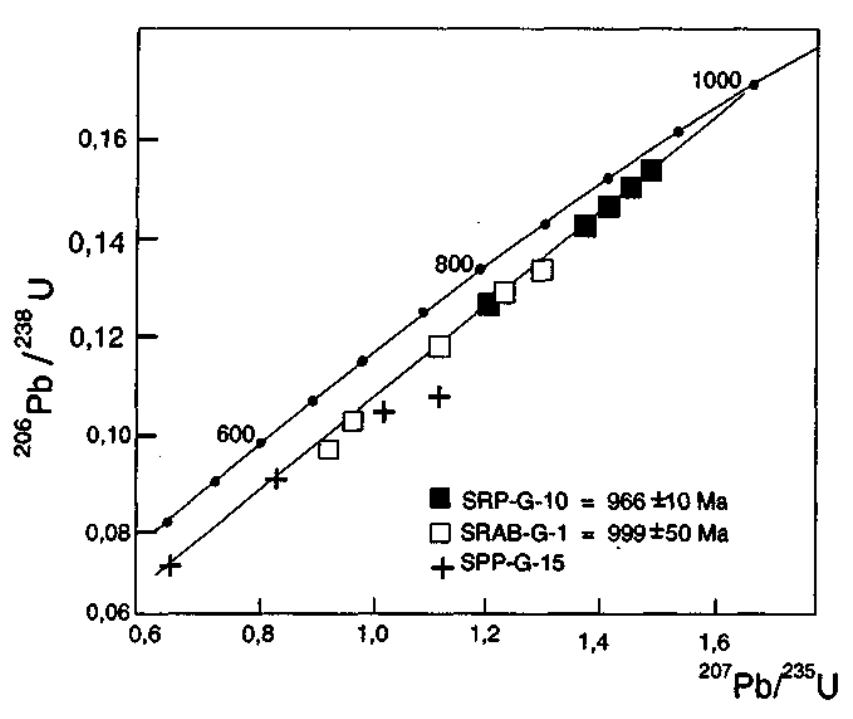

Figura 3 - Diagrama concórdia para os ortognaisses de Afeição (SRP-G-10, círculos pretos), Serra das Vassouras (SPAB-G-1, círculos claros) e os meta-granitóides São Pedro (SPP-G-15, cruzes). A corda de 1000 Ma é usada como referência (dados nas Tabelas $7 A, 7 B, 7 E$ ). Fonte: Van Schmus et al. (1995).

Figure 3 - Concórdia diagram showing zircon fractions from the orthogneisses of Afeição (SRP-G-10, black circles), Serra das Vassouras (SPAB-G-1, open circles) and São Pedo meta-granitoides (SPP-G-15, small crosses). $1000 \mathrm{Ma}$ chord is being used as age's reference (analytical data Tables 7A, 7B, 7E). After Van Schmus et al. (1995).

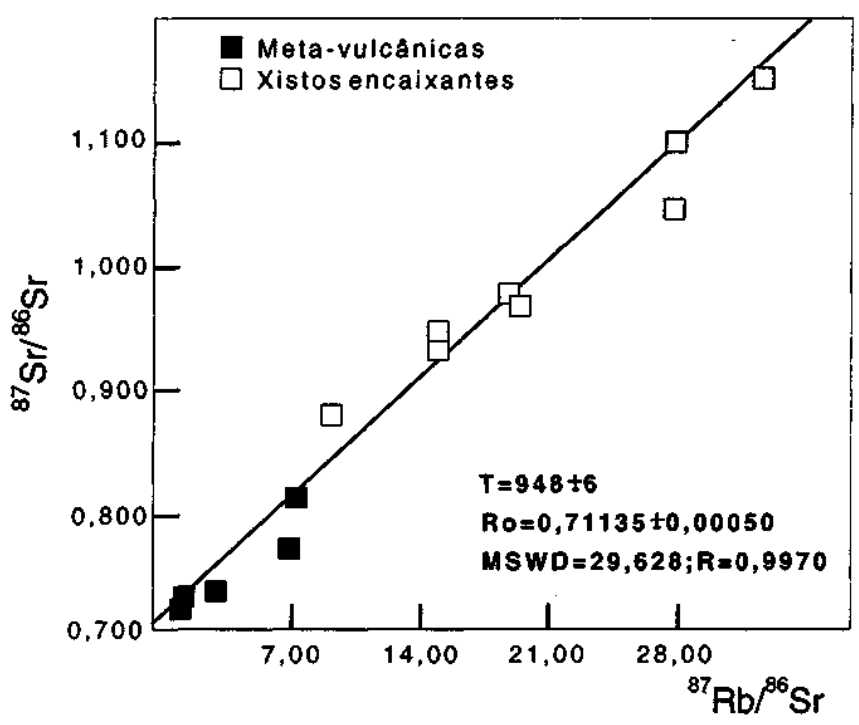

Figura 5 - Diagrama isocrônico para as meta-vulcânicas félsicas e xistos encaixantes do Riacho Gravata (Piaus), ao norte de Princeza Izabel-PB. Dados na Tabela 3. Figure $5-\mathrm{Rb} / \mathrm{Sr}$ isochronic diagram for the felsic meta-volcanic rocks and their enclosing schists of Gravata Creek, north of Princesa Isabel-PB. Analytical data Table 3 .

gráfica (SRP-V-65, a $4 \mathrm{Km}$ ao norte de Manaira), em metatufos ácidos com turmalina, foi obtida uma concórdia com intercepto superior indicando $\mathrm{T}=1126 \pm 16 \mathrm{Ma}$ (Fig. 6, Tabela 7).

Estes valores de idades são interpretados como da história vulcano-sedimentar, ou fase rifte, do ciclo em epígrafe, enquanto que os valores obtidos com o método Rb-Sr são

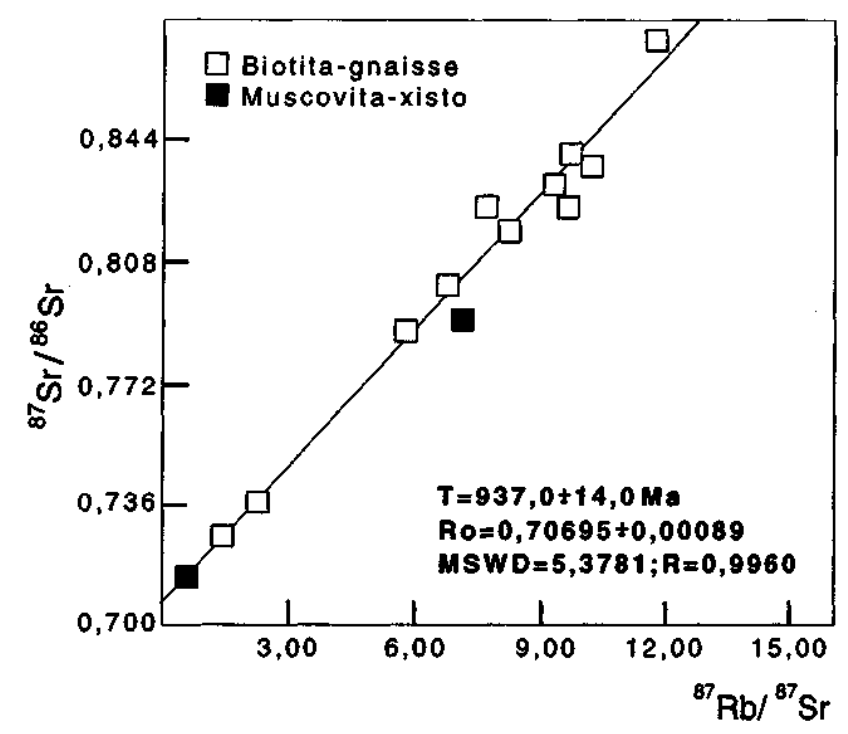

Figura 4 - Diagrama isocrônico para os gnaisses (e xistos) do Sistema Piancó-Alto Erigida ao sul de Salgueiro-PE. Dados na Tabela 2.

Figure $4-\mathrm{Rb} / \mathrm{Sr}$ isochronic diagram for gneisses (and schists) of the PiancóAlto Brfgida fold system, south of Salgueiro-PE. Analytical data Table 2.

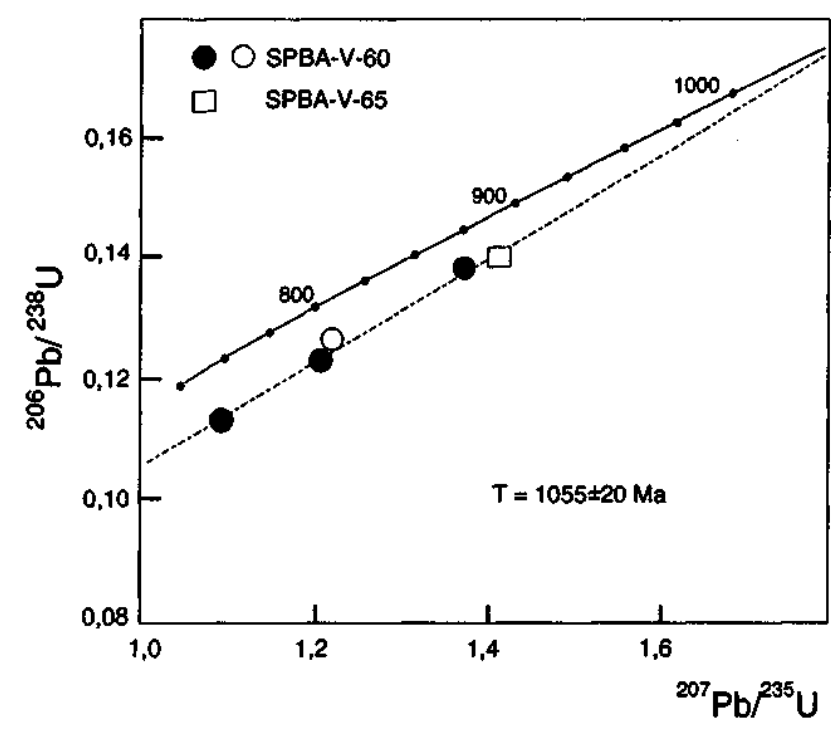

Figura 6 - Diagrama Concórdia para as rochas meta-vulcânicas do Riacho Gravata, em Piaus, SPAB-V-60, e do norte de Manaira, SPAB-V-65. O círculo aberto é uma f ração deSPAB$V$-60 não incluída na regressão. Outras frações mais discordantes de SPAB-V-65 foram também excluidas. Dados na Tabela 7. Fonte: Van Schmus et al.(1995a). Figure 6 - Concordia diagram showing zircons fractions from the felsic meta-volcanic rocks of Gravata Creek, sample SPAB-G-60, and from a roadcut north of Manaira-PB, sample SPAB-V-65. The open circle is a zircon fraction of SPAB-V-60 not included in the linear regression. Other more discordant zircon fractions from SPAB-V-65 were also excluded of the linear regression. Analytical data Table 7. After Van Schmus et al. (1995).

considerados como representativos do metamorfismo regional, pelos dados em si, e pela coerência com outros resultados aqui considerados neste sistema e em outros congéneres.

Para as rochas do Riacho Gravatá foram obtidos valores Sm-Nd, indicando Tdm = 2,08 e End ${ }_{600}=-9,6$ (amostra 60z), e $\mathrm{Tdm}=1,77 \mathrm{com} \operatorname{End}_{600}=-10,1$ (Tabela 8), que são valores compatíveis com derivação de material crustal para estas 
vulcânicas, e com demais resultados reportados neste texto. Para as unidades turbiditicas mais superiores não há dados geocronológicos disponíveis ainda.

\section{O SISTEMA PAJEÚ-PARAÍBA (SPP) Conceito e} conteúdo lito-estratigráfíco Este sistema foi recentemente revisto por Santos (1995), como já enfatizado, sintetizando ampla bibliografia preexistente, e introduzindo novos conceitos tectônicos e estratigráficos.

Foram definidos basicamente dois contextos de terrenos, ao norte do Lineamento Pernambuco (e do PEAL), a saber: $O$ terreno Alto Moxotó (TAM, ao sul e sudeste) e o terreno Alto Pajeú (TAP, ao norte, o qual inclui o batólito de Lagoa das Pedras), separados por uma zona de falhamento diagonal ao sistema.

O TAM é balizado ao sul pelo Lineamento Pernambuco, ao longo do qual aflora de forma dispersa o embasamento (Unidade Mulungu/Floresta, com extensão a Icaiçara, no SPAB, vide Fig. 1) de ortognaisses tonalíticos e granodioríticos, de idade paleoproterozóica. O TAP, porção mais ao norte do SPP, é basicamente constituido por uma associação vulcano-sedimentar (Complexo Cabrobó), ao sul do qual se intrudem "sheets graníticos" meta-aluminosos, trondhjemíticos ou de tendência trondhjemítica, e que forma corpos estratóides bastante contínuos, isto realçado pelo cisalhamento ao longo do Lineamento Pernambuco.

O Complexo Cabrobó é constituido por uma sequência de meta-sedimentos elásticos finos (QPC, quartzitos e pelitos e mais raramente níveis carbonáticos e ferríferos), e uma unidade vulcânica, com termos de natureza intermediária e subsidiariamente básica (Unidade Lagoa das Contendas), cujos dados geoquímicos são indicativos de ambiência em arcos continentais. Os "sheets" leucognáissicos são graníticos a granodioríticos (Unidade S. Pedro) e trondhjemíticos. Estas rochas também apresentam dados geoquímicos e outras características de geração em arcos magmáticos, que a julgar pela coerência dos dados isotópicos seriam de idade meso-neoproterozóica.

O TAP apresenta na base da sequência uma unidade de metabasitos e meta-ultramafitos (Unidade Pedras Pretas), muito variada em composição, bandamento e metamorfísmo, com alguns sedimentos subordinados, e que é caracterizada por bolsões e veios mineralizados em ilmenita. Os poucos dados geoquímicos disponíveis apontam para estas rochas (basaltos e picritos) geração em ambiente de fundos oceânicos. Sobreposto a este contexto aparece uma sequência vulcano-sedimentar, que é extensiva por todo o SPP, chamado de Complexo Sertânia, localmente desenvolvendo rochas migmatíticas. Neste, se destacam meta-tufos e metagrauvacas e rochas vulcânicas de composição dacítica, incluindo alguns derrames, rochas de caráter peraluminoso, com algumas intercalações locais de calcários e chertes, que constituem a Unidade Poço do Salgueiro. A contraparte metassedimentar, Sequência São Caetano, é composta essencialmente por xistos aluminosos, com vários tipos de intercalações, cálcio-silicáticas, e mais raramente quartzitos e chertes.

Como no TAM, o TAP também apresenta interposição com rochas graníticas estratóides, sendo neste caso rochas peraluminosas, que em parte, pelo menos, são fundidos anatéticos, os quais apresentam estruturas típicas de augen-gnaisses. São rochas de composição adamelítica a monzogranítica (Unidade Recanto), e monzogranítos com granada e muscovita (Unidade Riacho do Forno), este parcialmente migmatizado. Tanto os termos vulcânicos (Poço do Salgueiro), como estes plutônicos (Recanto e Riacho do Forno), a semelhança com as unidades ígneas do TAM, exibem dados geocronológicos do final do Mesoproterozóico.

Na região ao norte de Floresta-PE, no domínio do TAP se situa o batólito de Lagoa das Pedras, onde pontifica o grande corpo granodiorítco de Racho do Icó, alceado de forma discordante (transtração pós-Carirís Velhos), e cujos dados geocronológicos, coerentemente com a sua alocação, são do Neoproterozóico (em torno de 750 Ma, Santos 1995).

Os dados geocronológicos Resultados $\mathrm{U}-\mathrm{Pb}$ e $\mathrm{Sm}-\mathrm{Nd} d \mathrm{da}$ Área de Floresta-PE Os dados Sm-Nd e U-Pb deste sistema, de seu embasamento (Paleoproterozóico) e das intrusivas graníticas (neoproterozóicas) encontram publicados e comentados por Santos et al. (1995), e em parte por Van Schmus et al. (1995), cabendo aqui apenas uma síntese.

A suite Lagoa das Contendas (parte de TAM) por seus meta-tufos apresentou uma concórdia com intercepto superior de $1012 \pm 18 \mathrm{Ma}$, que foi interpretada como indicativa da idade do arco magmático. Por seu turno, zircões do meta-granitóide S. Pedro apresentaram um concórdia com alinhamento precário na corda, e intercepto superior próximo a $1150 \mathrm{Ma}$, o que ratifica o valor anteriormente encontrado.

A suíte Poço do Salgueiro (parte do TAP) apresentou uma concórdia com intercepto superior de $1089 \pm 143 \mathrm{Ma}$, novamente interpretada como representativa de idade do desenvolvimento do arco magmático. E os meta-granitóides de Recanto (augen-gnaisses como aqueles do "Alto TeixeiraTerra Nova", a serem discutidos) apresentaram bom alinhamento de corda com intercepto superior de $1037 \pm 30 \mathrm{Ma}$, então interpretado como representativo de evento de geração magmática sin-colisional da região.

Um pulso magmático pós-colisional importante foi reconhecido com a presença do batólito de granodiorito de Riacho do Icó, o qual apresentou diagrama concórdia com intercepto superior de $750 \pm 20 \mathrm{Ma}$, retratando já uma fase neoproterozóica da história regional, para cujos protólitos $(\mathrm{Tdm}=1,28$ Ga) é sugestiva uma procedência de materiais do Ciclo Carirís Velhos. De um modo geral, os valores de Tdm das rochas encaixantes, acima discutidas, ratificam valores do final do Paleoproterozóico ao Mesoproterozóico (1,76 a 1,20 Ga).

Resultado $\mathrm{Rb}-\mathrm{Sr}$ e outros Os resultados $\mathrm{Rb}-\mathrm{Sr}$ obtidos para o SPP se estendem consoante vários conjuntos litológicos de sudoeste para nordeste, sendo que neste arranjo serão computados dados já publicados (a serem mencionados) e vários outros ainda inéditos, formando um contexto geral bastante razoável e congruente.

Imediações Sul e Sudoeste de Carqueja Neste trato são incluídos os meta-granitóides colisionais (Santos 1995), tipo "Recanto" e "Riacho do Forno" e outras litologias similares já reportados por Lima et al. (1986). A isócrona agora obtida é de $\mathrm{T}=926 \pm 37$ Ma para $\mathrm{Ro}=0,71218 \pm 0,00292$ para 5 pontos computados (Tabela 4a, Fig. 7, com MSWD = 2,68). Imediações de Tuparetama-Afogados de Ingazeira-PE $\mathrm{Na}$ isócrona acima mencionada (e em outras a ela similares) se ajustam relativamente bem outros pontos analíticos de ortognaisses de várias localidades nas proximidades entre Afogados de Ingazeira e Tuparetama, discriminados na Tabela $4 \mathrm{~b}$, mas não computados na regessão linear, tendo em vista que a utilização dos mesmos não alteraria substancialmente o resultado final obtido, pelo menos nesta escala de análise. 
Tabela $4 a$ - Dados analíticos das determinações Rb/Sr nas imediações sul-sudoeste de Carqueja-PE. Table $4 \mathrm{a}$ - Analytical data for $\mathrm{Rb} / \mathrm{Sr}$ determinations on gneisses of the area south-southwest of Carqueja-PE.

\begin{tabular}{|c|c|c|c|c|c|c|c|c|c|c|}
\hline SPR & $\mathbf{N}^{\circ}$ Campo & Rocha & Material & $\mathbf{R b}$ (ppm) & Sr (ppm) & $\mathrm{Rb}^{87} / \mathrm{Sr}^{86}$ & $S r^{87} / S r^{86}$ & \multicolumn{2}{|c|}{ Coordenadas } & Obs. \\
\hline 7390 & $\mathrm{MI}-240.1$ & Granito gn. & R.T. & 299,1 & 90,4 & $7,407 \pm 0,207$ & $0,81217 \pm 0,00068$ & $8^{\circ} 21^{\prime} 16^{\prime \prime} S$ & $38^{\circ} 25^{\prime} 00^{\prime \prime} \mathrm{W}$ & $*$ \\
\hline 7391 & MI-240.7 & Granito gn. & $"$ & 226,6 & 138,0 & $4,786 \pm 0,134$ & $0,77921 \pm 0,00024$ & $8^{\circ} 21^{\prime} 16^{\prime \prime} \mathrm{S}$ & $38^{\circ} 25^{\prime} 00^{\prime} \mathrm{W}$ & $*$ \\
\hline 7392 & MI-240.8 & Granito gn. & $"$ & 231,0 & 89,4 & $7,912 \pm 0,221$ & $0,81556 \pm 0,00034$ & $8^{\circ} 21^{\prime} 16^{\prime \prime} \mathrm{S}$ & $38^{\circ} 25^{\prime} 00^{\prime \prime} \mathrm{W}$ & * \\
\hline 12678 & SPP-Gn-REC & Augen-gnaisse & $"$ & 224,0 & 82,0 & $7,989 \pm 0,224$ & $0,813640 \pm 0,000120$ & $8^{\circ} 22^{\prime} 00^{\prime} \mathrm{s}$ & $38^{\circ} 26^{\prime} 00^{\prime \prime} \mathrm{W}$ & \\
\hline 12679 & SPP-Gn-TAP & Granda-gnaisse & $"$ & 94,9 & 74,6 & $3,701 \pm 0,1040$ & $0,759250 \pm 0,000060$ & $8^{\circ} 23^{\prime} 03^{\prime \prime} S$ & $38^{\circ} 36^{\prime} 00^{\prime \prime} \mathrm{W}$ & \\
\hline
\end{tabular}

Obs: * Dados originais de Lima et al. 1986.

Tabela $4 b$ - Dados analíticos das determinações $\mathrm{Rb} / \mathrm{Sr}$ nas imediações de Afogados Ingazeira para Tuparetama-PE. Table $4 \mathrm{~b}$ - Analytical data for $\mathrm{Rb} / \mathrm{Sr}$ determinations on gneisses of the area between Afogados de Ingazeira-PE and Tuparetama-PE.

\begin{tabular}{|c|c|c|c|c|c|c|c|c|c|c|}
\hline SPR & $\mathbf{N}^{*}$ Campo & Rocha & Material & Rb (ppm) & Sr (ppm) & $\mathrm{Rb}^{87} / \mathrm{Sr}^{86}$ & $S r^{87} / S r^{86}$ & \multicolumn{2}{|c|}{ Coordenadas } & Obs. \\
\hline 12677 & SPP-Mi-RV & Diatexito & R.T. & 172,0 & 695,0 & $0,7170 \pm 0,020$ & $0,713790 \pm 0,00011$ & $7^{\circ} 44^{\prime} 14^{\prime \prime} \mathrm{S}$ & $37^{\circ} 21^{\prime} 05^{\prime \prime} \mathrm{W}$ & \\
\hline 12676 & SPP-Gn-SA & Bio-gnaisse & $"$ & 108,8 & 1650,4 & $0,1910 \pm 0,0050$ & $0,70732 \pm 0,000060$ & $7^{\circ} 44^{\prime} 10^{\prime \prime} \mathrm{S}$ & $37^{\circ} 41^{\prime} 15^{\prime \prime} \mathrm{W}$ & \\
\hline 12388 & SPP-Amp-CAN & Gn. anfibolítico & $"$ & 173,3 & 204,3 & $2,465 \pm 0,0690$ & $0,7479 \pm 0,000090$ & $7^{\circ} 53^{\prime} 15^{+} \mathrm{s}$ & $37^{\circ} 29^{\prime} 35^{\prime \prime} \mathrm{W}$ & \\
\hline
\end{tabular}

Tabela 4c - Dados analíticos das determinações Rb/Sr nas imediações ao norte de São José do Egito-PE. Table $4 \mathrm{c}$ - Analytical data for $\mathrm{Rb} / \mathrm{Sr}$ determinations on gneisses of the area north of São José do Egito-PE.

\begin{tabular}{|c|c|c|c|c|c|c|c|c|c|c|}
\hline SPR & $\mathrm{N}^{\circ}$ Campo & Rocha & Material & $\mathbf{R b}$ (ppm) & Sr (ppm) & $\mathrm{Rb}^{87} / \mathrm{Sr}^{86}$ & $\mathrm{Sr}^{87} / \mathrm{Sr}^{86}$ & \multicolumn{2}{|c|}{ Coordenadas } & Obs. \\
\hline 9458 & SM-1 & Gnaisse facoidal & R.T. & 213,7 & 84,9 & $7,3672 \pm 0,0990$ & $0,805310 \pm 0,000070$ & $7^{\circ} 26^{\prime} 00^{\prime \prime} \mathrm{S}$ & $37^{\circ} 22^{\prime} 26^{\prime \prime} \mathrm{W}$ & $*$ \\
\hline 9459 & SM-3 & Gnaisse facoidal & $"$ & 265,3 & 68,7 & $11,3510 \pm 0,3160$ & $0,866170 \pm 0,000050$ & $7^{\circ} 26^{\prime} 00^{\prime \prime} \mathrm{S}$ & $37^{\circ} 22^{\prime} 26^{\prime \prime} \mathrm{W}$ & * \\
\hline 9560 & SM-5 & Gnaisse facoidal & $"$ & 352,6 & 36,8 & $28,7269 \pm 0,4119$ & $1,049100 \pm 0,000070$ & $7^{\circ} 26^{\prime} 00^{\prime \prime} \mathrm{S}$ & $37^{\circ} 22^{\prime} 26^{\prime \prime} \mathrm{w}$ & $*$ \\
\hline 9461 & SM-6 & Gnaisse facoidal & $"$ & 274,0 & 43,3 & $18,7757 \pm 0,1642$ & $0,956290 \pm 0,000070$ & $7^{\circ} 26^{\circ} 00^{\prime \prime} \mathrm{S}$ & $37^{\circ} 22^{\prime} 26^{\prime \prime} \mathrm{W}$ & $*$ \\
\hline 9462 & SM-12 & Gnaisse facoidal & $"$ & 256,0 & 82,4 & $9,111 \pm 0,2540$ & $0,842290 \pm 0,000090$ & $7^{\circ} 26^{\prime} 00^{\prime \prime} \mathrm{S}$ & $37^{\circ} 22^{\prime} 26^{\prime \prime} \mathrm{W}$ & $*$ \\
\hline 13071 & SPP-Gn-ES & Augen-gnaisse & $"$ & 308,1 & 43,6 & $21,0100 \pm 0,5780$ & $0,984420 \pm 0,000080$ & $7^{\circ} 26^{\prime} 00^{\prime \prime} S$ & $37^{\circ} 22^{\prime} 26^{\prime \prime} \mathrm{W}$ & \\
\hline 13072 & SPP-Gn-FR & Ontogn. lamin. & $"$ & 216,5 & 56,4 & $11,2850 \pm 0,3140$ & $0,868000 \pm 0,000080$ & $7^{\circ} 25,37^{*} \mathrm{~S}$ & $37^{\circ} 25^{\prime} 25^{\prime} \mathrm{W}$ & \\
\hline 13070 & SPP-Gn-OA & Ortogn. lamin. & $"$ & 389,2 & 118.7 & $6,8490 \pm 0,1920$ & $0,819300 \pm 0,000030$ & $7^{\circ} 25^{\prime} 08^{\prime r} \mathrm{~S}$ & $37^{\circ} 16^{\prime} 55^{\prime \prime} \mathrm{W}$ & \\
\hline 13069 & SPP-Gn-AB $O$ & Augen-gnaisse & $"$ & 279,9 & 51,3 & $16,1140 \pm 0,4470$ & $0,915470 \pm 0,000230$ & $7^{\circ} 23^{\prime} 30^{\prime \prime} \mathrm{S}$ & $37^{\circ} 16^{\prime} 15^{\prime \prime} \mathrm{W}$ & \\
\hline 13126 & SPP-Gn-ABO2 & Augen-gnaisse & $"$ & 305,7 & 58,4 & $15,4630 \pm 0,4280$ & $0,917310 \pm 0,000160$ & $7^{\circ} 23^{\prime} 30^{\prime \prime} \mathrm{S}$ & $37^{\circ} 16^{\prime} 15^{\prime \prime} \mathrm{W}$ & \\
\hline
\end{tabular}

Obs: * Originais de Jardim de Sá 1994; com modificações.

Tabela 4d - Dados analíticos das determinações Rb/Sr nos Biotita-gnaisses granadíferos de Coxixola-PB. Table $4 \mathrm{~d}$ - Analytical data for $\mathrm{Rb} / \mathrm{Sr}$ determinations on biotite-garnet gneisses of the area of Coxixola-PB.

\begin{tabular}{|c|c|c|c|c|c|c|c|c|c|c|}
\hline SPR & $N^{\circ}$ Campo & Rocha & Material & $\mathbf{R b}(\mathbf{p p m})$ & Sr (ppm) & $\mathrm{Rb}^{87} / \mathrm{Sr}^{86}$ & $\mathrm{Sr}^{87} / \mathrm{Sr}^{86}$ & \multicolumn{2}{|c|}{ Coordenadas } & Obs. \\
\hline 782 & B-10-1 & Bio-gran. gnaisse & R.T. & 107,5 & 154,4 & $2,020 \pm 0,052$ & $0,7792 \pm 0,0021$ & $7^{\circ} 40^{\prime} 00^{\prime \prime} \mathrm{S}$ & $36^{\circ} 40^{\prime} 00^{\prime \prime} \mathrm{W}$ & * \\
\hline 786 & B-10-2 & Bio-gran. gnaisse & $"$ & 124,4 & 124,9 & $2,893 \pm 0,082$ & $0,7407 \pm 0,0022$ & $7^{\circ} 40^{\circ} 00^{\prime} \mathrm{S}$ & $36^{\circ} 40^{\prime} 00^{\prime \prime} \mathrm{W}$ & \\
\hline 772 & B-10-3 & Sillim,-gnaisse & $"$ & 64,5 & 710,0 & $0,264 \pm 0,07$ & $0,7115 \pm 0,0015$ & $7^{\circ} 40^{\prime} 00^{\prime \prime} \mathrm{S}$ & $36^{\circ} 40^{\circ} 00^{\circ} \mathrm{W}$ & \\
\hline 783 & B- $10-4$ & Granada-gnaisse & $*$ & 143,3 & 153,6 & $0,710 \pm 0,077$ & $0,7419 \pm 0,0017$ & $7^{\circ} 40^{\prime} 00^{\prime \prime} \mathrm{S}$ & $36^{\circ} 40^{\prime} 00^{\prime \prime} \mathrm{W}$ & \\
\hline 1252 & B-10-5 & Granada-gnaisse & $"$ & 102,0 & 115,6 & $2,560 \pm 0,050$ & $0,7372 \pm 0,0020$ & $7^{\circ} 40^{\prime} 00^{\prime \prime} S$ & $36^{\circ} 40^{\circ} 00^{\prime \prime} \mathrm{W}$ & \\
\hline
\end{tabular}




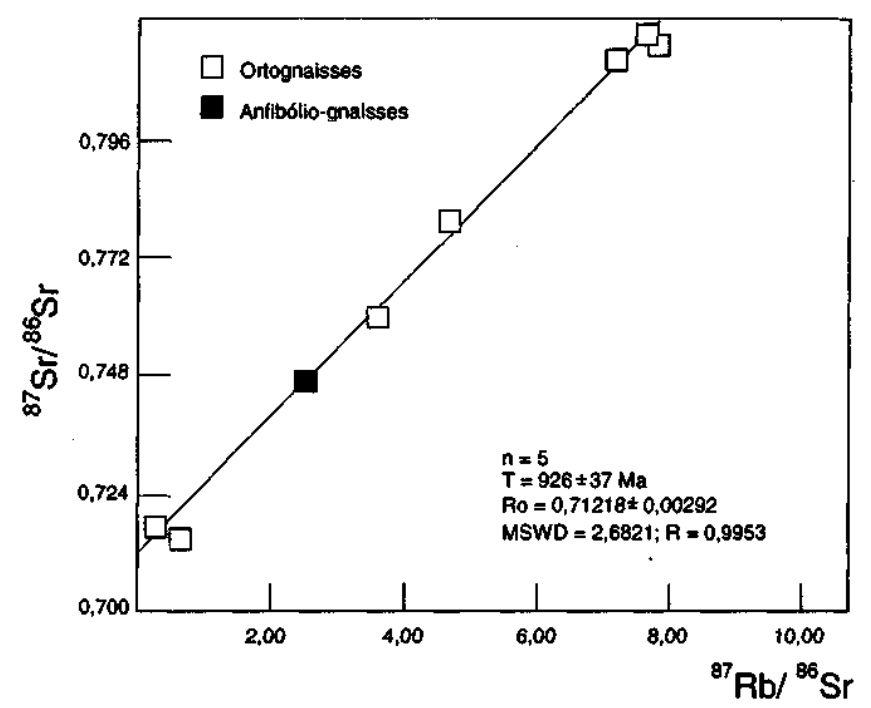

Figura 7 - Diagrama isocrônico para as rochas (orto)gnáissicas do Sistema Pajeú-Paraiba, imediações de Carqueja-PE, Afogados da Ingazeira-PE e Tuparetma-PE. Dados Tabelas $4 a e^{4}$.

Figure $7-\mathrm{Rb} / \mathrm{Sr}$ isochronic diagram for the orthogneissic rocks of the Pajeú-Paraiba fold system, of the surroundings of Carqueja-PE, Afogados de Ingazeira-PE and Tuparetama-PE. Analytical data Tables $4 a$ and $4 b$.

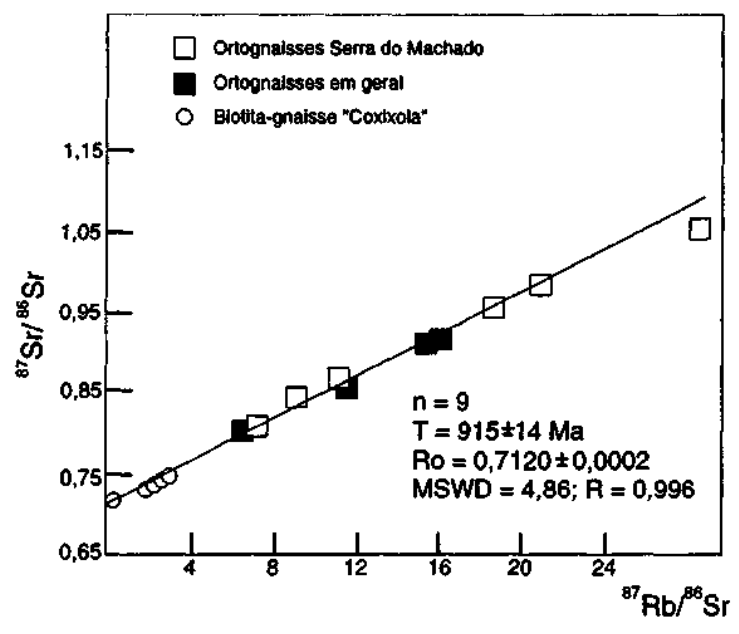

Figura 8 - Diagrama isocrônico para os ortognaisses nas imediações norte de S. José do Egito-PE, intercalados na pane norte de TAP. Alguns são dados preexistentes (Jardim de Sá, 1994) e outros são inéditos. No diagrama estão incluídos pontos de amostras de biotita-gnaisses granadiferos das proximidades de Coxixola-PB (de Brito Neves 1975). Dados nas Tabelas $4 c$ e $4 d$.

Figure $8-\mathrm{Rb} / \mathrm{Sr}$ isochronic diagram for the orthogneisses of the surroundings of São José do Egito-PE, northern part of TAP (Alto Pajeú terrane). Only some of these data are preexisting (Jardim de Sá 1994). On the same straight line were plotted data of a garnet-biotite gneisse (open circles) of CoxixolaPB (from Brito Neves 1975). Analytical data Tables 4c and 4d.

Tabela 5 - Dados analíticos das determinações Rb/Sr nos ortognaisses do "Alto Teixeira-Terra Nova". Table 5 - Analytical data for $\mathrm{Rb} / \mathrm{Sr}$ determinations on orthogneisses of the "Teixeira-Terra Nova Tectonic High".

\begin{tabular}{|c|c|c|c|c|c|c|c|c|c|c|}
\hline SPR & $\mathbf{N}^{\circ}$ Campo & Rocha & Material & $\mathbf{R b}(\mathbf{p p m})$ & $\mathbf{S r}(\mathbf{p p m}) \mid$ & $\mathrm{Rb}^{87} / \mathrm{Sr}^{86}$ & $\mathrm{Sr}^{87} / \mathrm{Sr}^{86}$ & \multicolumn{2}{|c|}{ Coordenadas } & Obs. \\
\hline 13067 & SL-Gn-DG & Ortognaisse & R.T. & 333,2 & 49,1 & $20,1510 \pm 0,550$ & $0,97151 \pm 0,000630$ & $7^{\circ} 20^{\prime} 00^{\prime \prime s}$ & $37^{\circ} 16^{\prime} 07^{\prime} \mathrm{W}$ & \\
\hline 13068 & SL-Gn-Gg & Ortogn. lamin. & $"$ & 386,6 & 50,3 & $22,8960 \pm 0,6290$ & $1,004800 \pm 0,000160$ & $7^{\circ} 22^{\prime} 27^{\prime \prime} \mathrm{s}$ & $37^{\circ} 16^{\prime} 48^{\prime \prime} \mathrm{W}$ & \\
\hline 13122 & SL-Gn-PP & Ortogn. lamin. & $"$ & 256,0 & 86,4 & $8,6770 \pm 0,2420$ & $0,822130 \pm 0,000080$ & $7^{\circ} 18^{\prime} 09^{\prime \prime} \mathrm{S}$ & $37^{\circ} 15^{\prime} 45^{\prime \prime} \mathrm{W}$ & \\
\hline 12675 & SL-Gn-PO & Ortogn. cinza & $"$ & 218,0 & 112,0 & $5,6770 \pm 0,1590$ & $0,787220 \pm 0,000110$ & $7^{\circ} 18^{\prime} 10^{\prime \prime} \mathrm{s}$ & $37^{\circ} 15^{\circ} 40^{\prime \prime} \mathrm{W}$ & \\
\hline 13123 & SL-Gn-Ax & Ortogn. lamin. & $"$ & 213,8 & 82,2 & $7,6070 \pm 0,2130$ & $0,814230 \pm 0,000070$ & $7^{\circ} 20^{\prime} 00^{\prime \prime} \mathrm{S}$ & $37^{\circ} 24^{\prime} 00^{\prime} \mathrm{W}$ & \\
\hline 12603 & SL-Gn-IMAI & Magn. ortogn. & $"$ & 254,2 & 85,3 & $8,7260 \pm 0,2440$ & $0,826630 \pm 0,000080$ & $7^{\circ} 23^{\prime} 00^{\prime \prime} \mathrm{s}$ & $37^{\circ} 50^{\prime} 50^{\prime \prime} \mathrm{W}$ & \\
\hline 13073 & SL-Gn-IMA2 & Magn. ortogn. & $"$ & 230,6 & 77,9 & $8,6690 \pm 0,2420$ & $0,828360 \pm 0,000130$ & $7^{\circ} 23^{\prime} 00^{\prime \prime} \mathrm{s}$ & $37^{\circ} 50^{\prime} 50^{\prime \prime} \mathrm{W}$ & \\
\hline 13167 & SL-Gn-DT & Augen-gnaisse & $"$ & 287,0 & 32,1 & $26,7996 \pm 0,3734$ & $1,082500 \pm 0,000130$ & $7^{\circ} 17^{\prime} 00^{\prime \prime s}$ & $37^{\circ} 05^{\prime} 10^{\prime \prime} \mathrm{W}$ & \\
\hline 12604 & SL-Gn-LVI & Ortogn. lamin. & $"$ & 283,2 & 56,5 & $14,7980 \pm 0,4100$ & $0,911160 \pm 0,000120$ & $7^{\circ} 24^{\prime} 30^{\prime \prime} \mathrm{S}$ & $37^{\circ} 34^{\prime} 15^{\prime \prime} \mathrm{W}$ & \\
\hline 13064 & SL-Gn-LV2 & Ortogn. Jamin. & $"$ & 235,7 & 75,2 & $9,1830 \pm 0,2570$ & $0,832520 \pm 0,000090$ & $7^{\circ} 24^{\prime} 30^{\prime} \mathrm{s}$ & $37^{\circ} 34^{\prime} 15^{\prime \prime} \mathrm{W}$ & \\
\hline 12602 & SL-Gn-GU1 & Ortogn. migm. & $"$ & 235,6 & 103,9 & $6,6160 \pm 0,1860$ & $0,790740 \pm 0,000110$ & 7'23'40's & $37^{\circ} 36^{\circ} 48^{\prime \prime} \mathrm{W}$ & \\
\hline 13075 & SL-Gn-GU2 & Ortogn. migm. & $"$ & 279,8 & 84,9 & $9,6590 \pm 0,2700$ & $0,836410 \pm 0,000080$ & $7^{\circ} 23^{\prime} 40^{\prime \prime} \mathrm{S}$ & $37^{\circ} 36^{\prime} 48^{\prime \prime} \mathrm{W}$ & \\
\hline 12605 & SL-Gn-AR & Ortogn. augen & $"$ & 256,7 & 81,7 & $9,2010 \pm 0,2570$ & $0,834940 \pm 0,000150$ & $7^{\circ} 27^{\prime} 30^{\prime \prime} \mathrm{s}$ & $37^{\circ} 34^{\prime} 24^{\prime} \mathrm{W}$ & \\
\hline 13120 & SL-Gn-EP & Gn. facoidal & $"$ & 263,4 & 55,6 & $13,9760 \pm 0,3880$ & $0,903590 \pm 0,000170$ & $7^{\circ} 28^{\prime} 48^{\prime \prime} \mathrm{s}$ & $37^{\circ} 37^{\circ} 04^{\prime \prime} \mathrm{W}$ & \\
\hline 12464 & SL-Gn-ABR1 & Ortognaisse & $"$ & 368,35 & 23,89 & $47,4826 \pm 0,6683$ & $1,363200 \pm 0,000440$ & $7^{\circ} 29^{\prime} 00^{\prime \prime} \mathrm{s}$ & $37^{\circ} 37^{\prime} 20^{\prime} \mathrm{W}$ & \\
\hline 12606 & SL-Gn-ABR2 & Ortognaisse & $"$ & 378,37 & 24,55 & $47,4400 \pm 0,6600$ & $1,358080 \pm 0,000170$ & $7^{\circ} 29^{\prime} 00^{\prime \prime} \mathrm{s}$ & $37^{\circ} 37^{\prime} 20^{\prime \prime} \mathrm{W}$ & \\
\hline 13166 & SL-Gn-ABR3 & Ortognaisse & & 356,03 & 22,83 & $48,0504 \pm 0,6698$ & $1,37030 \pm 0,002400$ & $"$ & $"$ & D.I. \\
\hline 13125 & L-Gn-BJ & Augen-gnaisse & $"$ & 226,9 & 87,4 & $7,5910 \pm 0,2120$ & $0,812750 \pm 0,000180$ & $7^{\circ} 26^{\prime} 24^{\prime \prime} \mathrm{S}$ & $37^{\circ} 11^{\prime} 07^{\prime \prime} \mathrm{W}$ & \\
\hline 13168 & SL-Gn-BEL & Ortognaisse & $"$ & 280,8 & 55,5 & $14,930 \pm 0,4140$ & $0,906450 \pm 0,000410$ & $7^{\circ} 34^{\prime} 50^{\prime \prime S}$ & $37^{\circ} 55^{\prime} 00^{\prime \prime} \mathrm{W}$ & \\
\hline 13124 & SL-Gn-AF & Ortogn. bandado & $"$ & 177,0 & 126,1 & $7,860 \pm 0,1150$ & $0,767190 \pm 0,000110$ & $7^{\circ} 42^{\prime} 19^{\prime \prime} \mathrm{S}$ & $37^{\circ} 54^{\prime} 00^{\prime \prime} \mathrm{W}$ & \\
\hline 13121 & SL-Gn-CD & Ortogn. bandado & $"$ & 367,2 & 67,2 & $16,1700 \pm 0,4470$ & $0,9359 \pm 0,000080$ & $7^{\circ} 44^{\prime} 00^{\prime \prime} \mathrm{s}$ & $37^{\circ} 57^{\prime} 10^{\prime \prime} \mathrm{W}$ & \\
\hline
\end{tabular}


Tabela $6 a$ - Dados analiticos das determinações Rb/Sr no Maciço PE-AL, ao norte de Cabrobó-PE. Table 6a - Analytical data for Rb/Sr determinations on gneisses of the PEAL Massif, área north of Cabrobó-PE.

\begin{tabular}{|c|c|c|c|c|c|c|c|c|c|c|}
\hline SPR & $\mathrm{N}^{\circ}$ Campo & Rocha & Material & $\mathbf{R b}$ (ppm) & Sr (ppm) & $\mathrm{Rb}^{87} / \mathrm{Sr}^{86}$ & $\mathrm{Sr}^{87} / \mathrm{Sr}^{86}$ & \multicolumn{2}{|c|}{ Coordenadas } & Obs. \\
\hline 6525 & DBSA-5 & Gn. migmatítico & R.T. & 324,3 & 158,0 & $6,00 \pm 0,168$ & $0,8079 \pm 0,0009$ & $8^{\circ} 22^{\prime} 45^{\prime \prime} \mathrm{s}$ & $39^{\circ} 23^{\prime} 00^{\prime \prime} w$ & $*$ \\
\hline 6526 & DBSA-6 & Gn. migmatítico & $"$ & 153,6 & 644,4 & $0,68 \pm 0,019$ & $0,7125 \pm 0,0004$ & $8^{\circ} 25^{\prime} 10^{\prime \prime} \mathrm{S}$ & $39^{\circ} 13^{\prime} 40^{\prime} \mathrm{W}$ & \\
\hline 6527 & DBSA-8 & Gn. migmatítico & $"$ & 182,6 & 179,1 & $2,96 \pm 0,083$ & $0,7454 \pm 0,0003$ & $8^{\circ} 25^{\prime} 30^{\prime \prime} \mathrm{S}$ & $39^{\circ} 22^{\prime} 00^{\prime} \mathrm{W}$ & \\
\hline 6528 & DBSA-9 & Gn. migmatítico & $"$ & 355,9 & 243,3 & $4,42 \pm 0,124$ & $0,7753 \pm 0,0004$ & $8^{\circ} 27^{\prime} 30^{\prime \prime} s$ & $39^{\circ} 23^{\prime} 30^{\prime \prime} \mathrm{W}$ & $*$ \\
\hline 6529 & DBSA-10 & Gn. migmatítico & $"$ & 334,2 & 97,6 & $10,00 \pm 0,280$ & $0,83081 \pm 0,00037$ & $8^{\circ} 23^{\prime} 18^{\prime \prime} \mathrm{S}$ & $39^{\circ} 24^{\prime} 30^{\prime \prime} \mathrm{W}$ & $* *$ \\
\hline 6547 & DBSA-11 & Gn. granítico & $"$ & 281,8 & 141,7 & $5,81 \pm 0,186$ & $0,79710 \pm 0,0001$ & $8^{\circ} 26^{\prime} 50^{\prime \prime} S$ & $39^{\circ} 22^{\prime} 00^{\prime \prime} \mathrm{W}$ & $*$ \\
\hline 6540 & DBSA-13 & Biotita-gnaisse & $"$ & 293.1 & 286,5 & $2,56 \pm 0,072$ & $0,7383 \pm 0,0001$ & $8^{\circ} 28^{\prime} 00^{\prime \prime} S$ & $39^{\circ} 11^{\prime} 00^{\prime} \mathrm{W}$ & \\
\hline 6549 & DBSA-16 & Diopsidio-gnaisse & $"$ & 218,0 & 158,6 & $3.99 \pm 0,112$ & $0,7582 \pm 0,0001$ & $8^{\circ} 27^{\prime} 30^{\prime \prime} \mathrm{S}$ & $39^{\circ} 24^{\prime} 10^{\prime} \mathrm{W}$ & \\
\hline 6550 & DBSA-19 & Biotita-gnaisse & $"$ & 249,3 & 207,3 & $3,49 \pm 0,098$ & $0,7591 \pm 0,0001$ & $8^{\circ} 29^{\prime} 18^{\prime \prime} \mathrm{S}$ & $39^{\circ} 14^{\prime} 40^{\prime \prime} \mathrm{W}$ & \\
\hline 6551 & DBSA-20 & Gn. granítico & $"$ & 165,1 & 245,0 & $1,95 \pm 0,055$ & $0,7281 \pm 0,0001$ & $8^{\circ} 28^{\prime} 50^{\prime \prime} \mathrm{S}$ & $39^{\circ} 06^{\prime} 40^{\prime} \mathrm{W}$ & \\
\hline 6552 & DBSA-21 & Gn granítico & " & 223,8 & 69,3 & $9,46 \pm 0,264$ & $0,8314 \pm 0,0001$ & $8^{\circ} 28^{\prime} 00^{\prime \prime} \mathrm{s}$ & $39^{\circ} 25^{\prime} 40^{\prime \prime} \mathrm{W}$ & \\
\hline 6553 & DBSA-22 & Gn. migmatítico & $"$ & 267,8 & 98,7 & $7,931 \pm 0,222$ & $0,8094 \pm 0,0001$ & $8^{\circ} 22$ '17's & $39^{\circ} 19^{\prime} 45^{\prime \prime} \mathrm{W}$ & \\
\hline 6554 & DBSA-23 & Gn. migmatítico & $"$ & 187,7 & 484,7 & $1,120 \pm 0,032$ & $0,7200 \pm 0,0001$ & $8^{\circ} 28^{\prime} 18^{\prime \prime} \mathrm{S}$ & $39^{\circ} 06^{\prime} 20^{\prime} \mathrm{W}$ & \\
\hline
\end{tabular}

Obs: * Originais em Brito Neves et al. 1984.

** Não computadas na isócrona da Fig. 7a.

Tabela $6 b$ - Dados analíticos das determinações Rb/Sr no Maciço PE-AL, nas imediações de Belém do São Francisco-PE. Tabela $6 \mathrm{~b}$ - Analytical data for $\mathrm{Rb} / \mathrm{Sr}$ determinations on gneisses of the PEAL Massif, área of the surroundings of Belém do S. Francisco-PE.

\begin{tabular}{|c|c|c|c|c|c|c|c|c|c|c|}
\hline SPR & $\mathbf{N}^{*}$ Campo & Rocha & Material & Rb (ppm) & Sr (ppm) & $\mathbf{R b}^{87} / \mathrm{Sr}^{86}$ & $\mathrm{Sr}^{87} / \mathrm{Sr}^{86}$ & \multicolumn{2}{|c|}{ Coordenadas } & Obs. \\
\hline 7382 & PE-535 & Gnaisse & R.T. & 183,9 & 98,6 & $5,441 \pm 0,153$ & $0,78819 \pm 0,00013$ & $8^{\circ} 44^{\prime} 10^{\prime \prime} \mathrm{S}$ & $38^{\circ} 56^{\prime} 11^{\prime \prime} \mathrm{W}$ & $*$ \\
\hline 7383 & PE-546 & " & $"$ & 129,3 & 866,2 & $0,432 \pm 0,012$ & $0,71055 \pm 0,00012$ & $8^{\circ} 44^{\prime} 10^{\prime \prime} \mathrm{S}$ & $38^{\circ} 57^{\prime} 10^{\prime \prime} \mathrm{W}$ & \\
\hline 7384 & PE-554.2 & $"$ & + & 90,1 & 141,4 & $1,849 \pm 0,052$ & $0,73501 \pm 0,00013$ & $8^{\circ} 43^{\prime} 20^{\prime \prime} \mathrm{S}$ & $38^{\circ} 56^{\prime} 10^{\prime \prime} \mathrm{W}$ & \\
\hline 7385 & PE-588.2 & $"$ & $"$ & 264,9 & 98,7 & $7,848 \pm 0,220$ & $0,81279 \pm 0,00031$ & $8^{\circ} 43^{\prime} 00^{\prime \prime} \mathrm{s}$ & $38^{\circ} 57^{\prime} 10^{\prime \prime} \mathrm{W}$ & \\
\hline 7386 & PE-588.4 & $"$ & $"$ & 291,2 & 64,9 & $13,243 \pm 0,367$ & $0,90843 \pm 0,00013$ & $8^{\circ} 43^{\prime} 00^{\prime \prime} \mathrm{S}$ & $38^{\circ} 57^{\prime} 10^{\prime \prime} \mathrm{W}$ & \\
\hline 7387 & PE-910.1 & $"$ & $"$ & 273,3 & 78,6 & $10,210 \pm 0,285$ & $0,85566 \pm 0,00018$ & $8^{\circ} 46^{\prime} 00^{\prime \prime} \mathrm{S}$ & $38^{\circ} 56^{\prime} 00^{\prime \prime} \mathrm{W}$ & \\
\hline 7388 & PE-616.2 & $"$ & $"$ & 211,7 & 194,3 & $3,168 \pm 0,089$ & $0,75390 \pm 0,00016$ & $8^{\circ} 45^{\prime} 00^{\prime \prime} \mathrm{s}$ & $38^{\circ} 55^{\circ} 00^{\prime \prime} \mathrm{W}$ & \\
\hline 7389 & PE-616.3 & $"$ & $"$ & 159,3 & 266,1 & $1,836 \pm 0,049$ & $0,73050 \pm 0,00047$ & $8^{\circ} 45^{\prime} 00^{\prime \prime S}$ & $38^{\circ} 55^{\prime} 00^{\prime \prime} \mathrm{W}$ & \\
\hline
\end{tabular}

Obs: * Fonte: Lima et al. 1986.

Tabela $6 c$ - Dados analiticos das determinações Rb/Sr no Maciço PE-AL, ao sul de Floresta-PE.

Table $6 \mathrm{c}$ - Analytical data for $\mathrm{Rb} / \mathrm{Sr}$ determinations on gneisses of PEAL Massif, area south of Floresta-PE.

\begin{tabular}{|c|c|c|c|c|c|c|c|c|c|c|}
\hline SPR & $\mathrm{N}^{\circ}$ Campo & Rocha & Material & $\mathbf{R b}(\mathbf{p p m})$ & Sr (ppm) & $\mathbf{R b} \mathbf{b}^{87} / \mathrm{Sr}^{86}$ & $\mathrm{Sr}^{87} / \mathrm{Sr}^{86}$ & \multicolumn{2}{|c|}{ Coordenadas } & Obs. \\
\hline 7421 & PE-519-1 & Gnaisse & R.T. & 194,7 & 155,9 & $3,633 \pm 0,102$ & $0,75939 \pm 0,00018$ & $8^{\circ} 39^{\prime} 15^{\prime \prime} \mathrm{S}$ & $38^{\circ} 42^{\prime} 30^{\prime \prime} \mathrm{W}$ & * \\
\hline 7422 & PE-702-1 & $"$ & $"$ & 122,6 & 203,0 & $1,753 \pm 0,049$ & $0,73637 \pm 0,00015$ & $8^{\circ} 38^{\prime} 20^{\prime \prime} \mathrm{S}$ & $38^{\circ} 37^{\prime} 06^{\prime \prime} \mathrm{W}$ & \\
\hline 7423 & PE-706 & $"$ & $"$ & 185,0 & 193,9 & $2,773 \pm 0,078$ & $0,74966 \pm 0,00008$ & $8^{\circ} 40^{\prime} 00^{\prime \prime} \mathrm{S}$ & $38^{\circ} 38^{\circ} 43^{\prime \prime} \mathrm{W}$ & \\
\hline 7424 & PE-711.1 & $"$ & $"$ & 105,3 & 511,0 & $0,597 \pm 0,017$ & $0,71551 \pm 0,00016$ & $8^{\circ} 39^{\prime} 00^{\prime \prime} S$ & $38^{\circ} 33^{\prime} 30^{+\prime} \mathrm{W}$ & $* *$ \\
\hline 7425 & PE-711.2 & $"$ & $"$ & 116,5 & 338,1 & $0,988 \pm 0,028$ & $0,71430 \pm 0,00020$ & $8^{\circ} 39^{\prime} 00^{\prime \prime S}$ & $38^{\circ} 33^{\prime} 30^{\prime \prime} \mathrm{W}$ & ** \\
\hline
\end{tabular}

Obs: * Dados originais de Lima et al. 1986.

** Não computados na isócrona da Fig. 5.

Área de São José do Egito e adjacências Nesta porção ao norte do chamado TAP, começam a ter grande expressão em área os ortognaisses (em "stocks", maciços e "sheets") de composição granítica a sienogranítica, que daí passam a perlongar o "Alto Teixeira-Terra Nova", inclusive servindo de encaixantes para os plútons (granitos e sienitos) aí claramente intrusivos, de idades neoproterozóicas. Desta forma, este "alto" adquire características geomórficas importantes, formando e suportando a zona elevada de interflúvios e de fronteira Pernambuco-Paraiba.

A separação dos dados agora comentados (9 de 10 amostras, sendo 5 delas da Serra do Machado, ao norte de S. José do Egito) são de ocorrências localizadas ao sul do paralelo de Brejinho-PE, onde se localiza um plúton neoproterozóico 
Tabela 7 - Dados analíticos das determinações $U / P b$.

Table 7 - Analytical data for the $\mathrm{U} / \mathrm{Pb}$ determinations.

$7 A=$ SRP-G-10 = Augen-gnaisse de Afeição (Fig. 3).

Coord.: $8^{\circ} 10^{\prime} 30^{\prime}$ 'S; $40^{\circ} 59^{\prime} 00^{\prime \prime} \mathrm{W}$

\begin{tabular}{|c|c|c|c|c|c|c|c|c|c|c|}
\hline \multirow[b]{2}{*}{ Fração } & \multicolumn{3}{|c|}{ Concentraçōes $^{2}$} & \multirow{2}{*}{$\frac{\text { Observ. }^{3}}{{ }^{206} \mathrm{~Pb} /{ }^{204} \mathrm{~Pb}}$} & \multicolumn{3}{|c|}{ Razões Atômicas ${ }^{4}$} & \multicolumn{3}{|c|}{ Idades $(\mathbf{M a})^{5}$} \\
\hline & Peso & $\mathbf{U}$ & $\mathbf{P b}$ & & ${ }^{206} \mathrm{~Pb} /{ }^{238} \mathrm{U}$ & ${ }^{207} \mathrm{~Pb} /{ }^{235} \mathrm{U}$ & ${ }^{207} \mathrm{~Pb} /{ }^{206} \mathrm{~Pb}$ & ${ }^{206} \mathrm{~Pb} /{ }^{238} \mathrm{U}$ & ${ }^{207} \mathrm{~Pb} /^{235} \mathbf{U}$ & ${ }^{207} \mathrm{~Pb} /{ }^{206} \mathrm{~Pb}$ \\
\hline $\operatorname{NM}(-1)$ & 0,538 & 272 & 44 & 2,320 & 0,14896 & 1,4630 & 0,07123 & 895 & 915 & 964 \\
\hline$M(-1)$ & 0,553 & 255 & 48 & 370 & 0,14966 & 1,4779 & 0,07148 & 899 & 920 & 971 \\
\hline $\mathrm{M}(-1) \mathrm{E}, \mathrm{C}$ & 0,646 & 305 & 43 & 1,135 & 0,12402 & 1,227 & 0,07150 & 753 & 811 & 972 \\
\hline $\mathrm{M}(0) \mathrm{E}, \mathrm{C}$ & 0,682 & 276 & 44 & 1,614 & 0,14378 & 1,4152 & 0,07139 & 866 & 895 & 968 \\
\hline $\mathrm{M}(1) \mathrm{E}, \mathrm{C}$ & 0,469 & 281 & 44 & 1,502 & 0,14056 & 1,3818 & 0,07130 & 848 & 881 & 966 \\
\hline
\end{tabular}

Regressão: I.S. $=966 \pm 10 \mathrm{Ma}$; I.I. $=-25 \pm 94$

$7 A^{\prime}$ - SRP-G-10' = Augen-gnaisse de Afeição* (Jardim de Sá 1994).

\begin{tabular}{|c|c|c|c|c|c|c|c|c|c|c|}
\hline \multirow[b]{2}{*}{ Fração } & \multicolumn{3}{|c|}{ Concentrações $^{2}$} & \multirow{2}{*}{$\frac{\text { Observ. }^{3}}{{ }^{206} \mathrm{~Pb} /{ }^{204} \mathrm{~Pb}}$} & \multicolumn{3}{|c|}{ Razões Atômicas ${ }^{4}$} & \multicolumn{3}{|c|}{ Idades $(\mathbf{M a})^{5}$} \\
\hline & Peso & $\mathbf{U}$ & $\mathbf{P b}$ & & ${ }^{206} \mathrm{~Pb} /{ }^{238} \mathrm{U}$ & ${ }^{207} \mathrm{~Pb} / /^{235} \mathrm{U}$ & ${ }^{207} \mathrm{~Pb} /{ }^{206} \mathrm{~Pb}$ & ${ }^{206} \mathrm{~Pb} /{ }^{238} \mathrm{U}$ & ${ }^{207} \mathrm{~Pb} /{ }^{235} \mathrm{U}$ & ${ }^{207} \mathrm{~Pb} /{ }^{206} \mathrm{~Pb}$ \\
\hline $\mathrm{A}$ & & 58,5 & 648,6 & 651.7 & $0,8455 \pm 24$ & $0,08601 \pm 16$ & $0,09129 \pm 16$ & & & \\
\hline B & & 75,0 & 724,8 & 758,56 & $0,9915 \pm 64$ & $0,10025 \pm 19$ & $0,07172 \pm 14$ & & & \\
\hline $\mathrm{C}$ & & 81,7 & 813,6 & 931,86 & $0,9622 \pm 59$ & $0,097108 \pm 18$ & $0,07186 \pm 15$ & & & \\
\hline D & & 58,8 & 753,0 & 460,12 & $0,7472 \pm 79$ & $0,075404 \pm 17$ & $0,07187 \pm 19$ & & & \\
\hline
\end{tabular}

Regressão: I.S. $=986 \pm 48$ Ma; I.I. $=18+76$

$7 B=S P A B-G-1=$ Ortognaisse micáceo Vassouras (Fig. 3).

Coord.: $08^{\circ} 16^{\prime} 08^{\prime \prime} S$; $39^{\circ} 03^{\prime} 05^{\prime \prime} W$

\begin{tabular}{|c|c|c|c|c|c|c|c|c|c|c|}
\hline \multirow[b]{2}{*}{ Fração } & \multicolumn{3}{|c|}{ Concentrações $^{2}$} & \multirow{2}{*}{$\frac{\text { Observ }^{3}}{{ }^{206} \mathrm{~Pb} /^{204} \mathrm{~Pb}}$} & \multicolumn{3}{|c|}{ Razões Atômicas ${ }^{4}$} & \multicolumn{3}{|c|}{ Idades $(\mathbf{M a})^{5}$} \\
\hline & Peso & $\mathbf{U}$ & $\mathbf{P b}$ & & ${ }^{206} \mathrm{~Pb} /{ }^{238} \mathrm{U}$ & ${ }^{207} \mathrm{~Pb} /{ }^{235} \mathrm{U}$ & ${ }^{207} \mathrm{~Pb} /{ }^{206} \mathrm{~Pb}$ & ${ }^{206} \mathrm{~Pb} / /^{238} \mathrm{U}$ & ${ }^{207} \mathrm{~Pb} / /^{235} \mathrm{U}$ & ${ }^{207} \mathrm{~Pb} / /^{206} \mathrm{~Pb}$ \\
\hline $\mathrm{NM}(0) \mathrm{E}, \mathrm{Y}, \mathrm{F}$ & 0,097 & 270 & 42 & 2763 & 0,14947 & 1,4977 & 0,07267 & 898 & 930 & 1005 \\
\hline$N M(0)$ pink & 0,599 & 379 & 55 & 33,5 & 0,13091 & 1,2942 & 0,07170 & 793 & 843 & 977 \\
\hline NM $(0)$ bulk & 1,038 & 357 & 50 & 458 & 0,12762 & 1,2283 & 0,06981 & 774 & 814 & 923 \\
\hline $\mathrm{M}(0) \mathrm{E}, \mathrm{Y}, \mathrm{F}$ & 0,171 & 396 & 56 & 1618 & 0,13501 & 1,3222 & 0,07103 & 816 & 856 & 958 \\
\hline $\mathrm{M}(0)$ bulk & 1,018 & 438 & 54 & 391 & 0,11578 & 1,1162 & 0,06992 & 706 & 761 & 926 \\
\hline $\mathrm{M}(1) \mathrm{E}, \mathrm{Y}, \mathrm{F}$ & 0,073 & 436 & 55 & 1302 & 0,12112 & 1,1984 & 0,07057 & 737 & 791 & 945 \\
\hline $\mathrm{M}(1)$ bulk & 1,247 & 573 & 60 & 613 & 0,10064 & 0,9661 & 0,06962 & 918 & 687 & 917 \\
\hline$M(2)$ bulk & 0,488 & 656 & 69 & 379 & 0,09686 & 0,9384 & 0,07026 & 596 & 672 & 936 \\
\hline
\end{tabular}

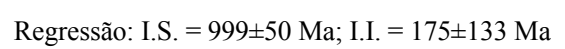

\section{$7 C=S P A B-V-60$}

Coord.: $07^{\circ} 36^{\prime} 04^{\prime \prime} S$; $38^{\circ} 02^{\prime} 30^{\prime \prime} W$

\begin{tabular}{|c|c|c|c|c|c|c|c|c|c|c|}
\hline \multirow[b]{2}{*}{ Fração } & \multicolumn{3}{|c|}{ Concentraçōes ${ }^{2}$} & \multirow{2}{*}{$\frac{\text { Observ }^{3}}{{ }^{206} \mathrm{~Pb} /{ }^{204} \mathrm{~Pb}}$} & \multicolumn{3}{|c|}{ Razões Atômicas ${ }^{4}$} & \multicolumn{3}{|c|}{ Idades $(\mathbf{M a})^{5}$} \\
\hline & Peso & $\mathbf{U}$ & $\mathbf{P b}$ & & ${ }^{206} \mathrm{~Pb} /{ }^{238} \mathrm{U}$ & ${ }^{207} \mathrm{~Pb} / /^{235} \mathrm{U}$ & ${ }^{207} \mathrm{~Pb} /^{206} \mathrm{~Pb}$ & ${ }^{206} \mathrm{~Pb} /{ }^{238} \mathrm{U}$ & ${ }^{207} \mathrm{~Pb} r^{235} \mathrm{U}$ & ${ }^{207} \mathrm{~Pb} /{ }^{206} \mathrm{~Pb}$ \\
\hline NM(-1) bulk & 0,224 & 254 & 43 & 237 & 0,13852 & 1,3721 & 0,07184 & 836 & 877 & 981 \\
\hline $\mathrm{NM}(-1)$ bulk $\mathrm{n} / \mathrm{a}$ & 0,750 & 297 & 54 & 160 & 0,12678 & 1,2123 & 0.06935 & 770 & 806 & 909 \\
\hline M(-1) bulk n/a & 0,880 & 464 & 78 & 175 & 0,12386 & 1,2071 & 0,07086 & 753 & 804 & 948 \\
\hline $\mathrm{M}(0)$ bulk $\mathbf{n} / \mathbf{a}$ & 1,344 & 818 & 106 & 372 & 0,11334 & 1,0839 & 0,06936 & 692 & 746 & 909 \\
\hline
\end{tabular}

Regressão: I.S. = 1055+20 Ma; I.I. $=329 \pm 150 \mathrm{Ma}$ 
$7 D=S P A B-V-65$

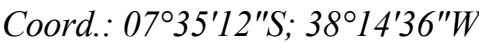

\begin{tabular}{|c|c|c|c|c|c|c|c|c|c|c|}
\hline & \multicolumn{3}{|c|}{ Concentrações $^{2}$} & Observ. $^{3}$ & \multicolumn{4}{c|}{ Razões Atômicas $^{4}$} & \multicolumn{3}{c|}{ Idades (Ma) $^{\mathbf{5}}$} \\
\hline Fração & Peso & $\mathbf{U}$ & $\mathbf{P b}$ & ${ }^{206} \mathbf{P b} /{ }^{204} \mathbf{P b}$ & ${ }^{206} \mathbf{P b} /{ }^{238} \mathbf{U}$ & ${ }^{207} \mathbf{P b} /{ }^{235} \mathbf{U}$ & ${ }^{207} \mathbf{P b} /{ }^{206} \mathbf{P b}$ & ${ }^{206} \mathbf{P b} /^{238} \mathbf{U}$ & ${ }^{207} \mathbf{P b} /{ }^{235} \mathbf{U}$ & ${ }^{207} \mathbf{P b} /{ }^{206} \mathbf{P b}$ \\
\hline NM(1) bulk & 0,523 & 256 & 58 & 131 & 0,14070 & 1,4006 & 0,07219 & 849 & 889 & 991 \\
\hline NM(1) bulk n/2 & 1,452 & 450 & 72 & 104 & 0,09184 & 0,7988 & 0,06240 & 572 & 596 & 688 \\
\hline
\end{tabular}

Regressão: I.S. $=1055 \pm 20$ Ma; I.I. $=329 \pm 50 \mathrm{Ma}$

$7 D=S P P-B M-B r o w n=$ Sequência Lagoa das Contendas

Coord.: $8^{\circ} 33^{\prime} 00^{\prime \prime} S$; $38^{\circ} 35^{\prime} 00^{\prime \prime} W$

\begin{tabular}{|c|c|c|c|c|c|c|c|c|c|c|}
\hline & \multicolumn{2}{|c|}{ Concentrações $^{2}$} & Observ $^{3}$ & \multicolumn{3}{c|}{ Razões Atômicas } & \multicolumn{3}{c|}{ Idades (Ma) $^{\mathbf{5}}$} \\
\hline Fração & Peso & $\mathbf{U}$ & $\mathbf{P b}$ & ${ }^{206} \mathbf{P b} /{ }^{204} \mathbf{P b}$ & ${ }^{206} \mathbf{P b} /{ }^{238} \mathbf{U}$ & ${ }^{207} \mathbf{P b} /{ }^{235} \mathbf{U}$ & ${ }^{207} \mathbf{P b} /{ }^{206} \mathbf{P b}$ & ${ }^{206} \mathbf{P b} /{ }^{238} \mathbf{U}$ & ${ }^{207} \mathbf{P b} /{ }^{235} \mathbf{U}$ & ${ }^{207} \mathbf{P b} /{ }^{206} \mathbf{P b}$ \\
\hline $\mathrm{NM}(0)$ & 0,088 & 221 & 41 & 655 & 0,15764 & 1,5627 & 0,07189 & 944 & 956 & 983 \\
\hline $\mathrm{M}(0)$ & 0,064 & 231 & 42 & 597 & 0,15486 & 1,5293 & 0,07162 & 928 & 942 & 975 \\
\hline $\mathrm{M}(1)$ & 0,078 & 345 & 59 & 929 & 0,14562 & 1,4197 & 0,07071 & 876 & 897 & 949 \\
\hline
\end{tabular}

Regressão: I.S. $=1.012 \pm 18 \mathrm{Ma} ; \mathrm{LI} .=472 \pm 91 ; \mathrm{P}=0,91$

$7 E=S P P-G-15=$ Metagranitóide São Pedro

Coord.: $8^{\circ} 33^{\prime} 04^{\prime \prime} S$; $38^{\circ} 35^{\prime} 03^{\prime \prime} W$

\begin{tabular}{|c|c|c|c|c|c|c|c|c|c|c|}
\hline & \multicolumn{2}{|c|}{ Concentraçós $^{2}$} & Observ $^{3}$ & \multicolumn{4}{|c|}{ Razöes Atômicas $^{4}$} & \multicolumn{3}{c|}{ Idades (Ma) $^{\mathbf{5}}$} \\
\hline Fração & Peso & $\mathbf{U}$ & $\mathbf{P b}$ & ${ }^{206} \mathbf{P b} /{ }^{204} \mathbf{P b}$ & ${ }^{206} \mathbf{P b} /{ }^{238} \mathbf{U}$ & ${ }^{207} \mathbf{P b} /{ }^{235} \mathbf{U}$ & ${ }^{207} \mathbf{P b} /{ }^{206} \mathbf{P b}$ & ${ }^{206} \mathbf{P b} /{ }^{238} \mathbf{U}$ & ${ }^{207} \mathbf{P b} /{ }^{235} \mathbf{U}$ & ${ }^{207} \mathbf{P b} /{ }^{206} \mathbf{P b}$ \\
\hline M(0)E & 0,146 & 1012 & 118 & 568 & 0,10670 & 1,1253 & 0,07647 & 654 & 766 & 1107 \\
\hline NM(0)E & 0,115 & 609 & 59 & 627 & 0,10510 & 1,0369 & 0,07155 & 644 & 722 & 973 \\
\hline M(2)E & 0,114 & 1068 & 108 & 470 & 0,09115 & 0,8569 & 0,06818 & 562 & 629 & 874 \\
\hline M(4)E & 0,052 & 1392 & 88 & 213 & 0,07338 & 0,6499 & 0,06422 & 457 & 508 & 749 \\
\hline
\end{tabular}

Regressão não realizada: contém xenocristais mais antigos

$7 F=S P P-V-P S=$ Sequência Poço do Salgueiro

Coord.: $8^{\circ} 22^{\prime} 02^{\prime \prime} S$; $38^{\circ} 28^{\prime} 02^{\prime \prime} W$

\begin{tabular}{|c|c|c|c|c|c|c|c|c|c|c|}
\hline & \multicolumn{2}{|c|}{ Concentrações $^{2}$} & Observ $^{3}$ & \multicolumn{3}{c|}{ Razões Atômicas $^{4}$} & \multicolumn{3}{c|}{ Idades (Ma) $^{5}$} \\
\hline Fração & Peso & $\mathbf{U}$ & $\mathbf{P b}$ & ${ }^{{ }^{206}} \mathbf{P b} /{ }^{204} \mathbf{P b}$ & ${ }^{206} \mathbf{P b} /{ }^{238} \mathrm{U}$ & ${ }^{207} \mathbf{P b} /{ }^{235} \mathbf{U}$ & ${ }^{207} \mathbf{P b} /{ }^{206} \mathbf{P b}$ & ${ }^{206} \mathbf{P b} /{ }^{238} \mathbf{U}$ & ${ }^{207} \mathbf{P b} /{ }^{235} \mathbf{U}$ & ${ }^{207} \mathbf{P b} /{ }^{206} \mathbf{P b}$ \\
\hline $\mathrm{M}(-1) \mathrm{E}$ & 0,443 & 267 & 45 & 8403 & 0,15308 & 1,5504 & 0,07346 & 918 & 951 & 1027 \\
\hline $\mathrm{M}(0) \mathrm{E}$ & 0,575 & 400 & 65 & 8475 & 0,14763 & 0,4656 & 0,07200 & 888 & 916 & 986 \\
\hline $\mathrm{M}(1) \mathrm{E}$ & 0,106 & 663 & 99 & 4545 & 0,13922 & 1,3694 & 0,07200 & 840 & 876 & 967 \\
\hline $\mathrm{M}(2) \mathrm{E}$ & 0,094 & 476 & 70 & 2591 & 0,13676 & 1,3506 & 0,07162 & 826 & 868 & 975 \\
\hline
\end{tabular}

Regressão: I.S. $=1.089+143$ Ma; I.I. $=460 \pm 210 ; \mathrm{P}<0,01$

$7 G=S P P-G n-R E L=$ Augen-gnaisse Recanto

Coord.: $08^{\circ} 22^{\prime} 02^{\prime}$ 'S; $38^{\circ} 26 W^{\prime \prime} W$

\begin{tabular}{|c|c|c|c|c|c|c|c|c|c|c|}
\hline & \multicolumn{2}{|c|}{ Concentrações $^{2}$} & Observ. $^{3}$ & \multicolumn{4}{|c|}{ Razões Atômicas $^{4}$} & \multicolumn{3}{c|}{ Idades (Ma) $^{5}$} \\
\hline Fração & Peso & $\mathbf{U}$ & $\mathbf{P b}$ & ${ }^{206} \mathbf{P b} /{ }^{204} \mathbf{P b}$ & ${ }^{206} \mathbf{P b} /{ }^{238} \mathbf{U}$ & ${ }^{207} \mathbf{P b} /{ }^{235} \mathbf{U}$ & ${ }^{207} \mathbf{P b} /{ }^{206} \mathbf{P b}$ & ${ }^{206} \mathbf{P b} /{ }^{238} \mathbf{U}$ & ${ }^{207} \mathbf{P b} /{ }^{235} \mathbf{U}$ & ${ }^{207} \mathbf{P b} /{ }^{206} \mathbf{P b}$ \\
\hline NM(0) bulk & 0,444 & 364 & 53 & 12.195 & 0,14898 & 1,4793 & 0,07202 & 895 & 922 & 986 \\
\hline M(0) & 0,572 & 518 & 73 & 11.363 & 0,14482 & 1,4232 & 0,07127 & 872 & 899 & 965 \\
\hline M(1) & 0,654 & 473 & 65 & 3623 & 0,13912 & 1,3606 & 0,07093 & 840 & 872 & 956 \\
\hline M(2)EU(9) & 0,014 & 737 & 91 & 2315 & 0,12849 & 1,2360 & 0,06970 & 779 & 817 & 920 \\
\hline
\end{tabular}

Regressão: I.S. $=1.037 \pm 30 \mathrm{Ma}$; I.I. $=732 \pm 100$

Obs: $\mathrm{NM}=$ não magnético; $\mathrm{M}=$ magnético; $\mathrm{n}^{\circ}$ entre parênteses indica inclinação lateral do Franz a potência de 1,5 amp.;

$\mathrm{C}=$ fração grossa $(>200$ mesh); $\mathrm{E}=$ grãos euedrais longos; $\mathrm{R}=$ grãos arredondados; $\mathrm{C}=$ grãos claros internamente; $\mathrm{F}$ = grãos externamente embaçados;

$\mathrm{T}=$ grãos internamente translúcidos;

$\mathrm{P}=$ cor púrpura; $\mathrm{Y}=$ cor amarela; $\mathrm{n} / \mathrm{a}=$ não abradados. 
Tabela 8 - Dados analíticos das determinações $\mathrm{Sm} / \mathrm{Nd}$

Table 8 - Analytical data for the $\mathrm{Sm} / \mathrm{Nd}$ determinations.

\begin{tabular}{|c|c|c|c|c|c|c|c|c|c|c|c|}
\hline Amostra & Rocha & $\begin{array}{c}\text { Nd } \\
(\mathrm{ppm})\end{array}$ & $\underset{(\mathbf{p p m})}{\mathbf{S m}}$ & $\mathrm{Sm}^{147} \mathrm{Nd}^{144}$ & ENd ( ) & $\underset{\mathrm{Ma}}{\mathrm{ENd600}}$ & $\begin{array}{l}\text { Idade } \\
\text { (Ga) }\end{array}$ & ENd & $\sigma \mathrm{DM}(\mathrm{Ga})$ & \multicolumn{2}{|c|}{ Coordenadas } \\
\hline SRP-G-J0 & $\begin{array}{l}\text { Augen-gnaisse } \\
\text { Afejção }\end{array}$ & 42,85 & 8,73 & 0,1232 & $-9,1$ & $-3,4$ & 0,97 & 0,1 & 1,46 & $08^{\circ} 10^{\prime} 30^{\prime \prime} \mathrm{s}$ & $40^{\circ} 34^{\prime} 00^{\prime} \mathrm{W}$ \\
\hline SPAB-G-1 & Muscovita-granito & 38,63 & 8,50 & 0,13312 & $-9,5$ & $-4,6$ & 0,95 & $-1,8$ & 1,68 & $08^{\circ} 16^{\prime} 05^{\prime \prime} \mathrm{s}$ & $39^{\circ} 03^{\prime} 03^{\prime} \mathrm{W}$ \\
\hline SPAB-G-Ia & $\begin{array}{l}\text { Muscovita-granito } \\
\text { (Sa Vassouras) }\end{array}$ & 22,96 & 5,07 & 0,13352 & -9.7 & $-4,9$ & 0,95 & - & 1,92 & $08^{\circ} 16^{\circ} 05^{\circ} \mathrm{s}$ & $39^{\circ} 03^{\prime} 03^{\circ} \mathrm{W}$ \\
\hline SPAB-V-60b & Meta-riolito & 65,63 & 11.19 & 0,10307 & $-17,2$ & -10.1 & 1,02 & $=$ & 1,77 & $07^{\circ} 36^{\prime} 04^{\prime \prime} \mathrm{s}$ & $38^{\circ} 02^{\prime} 30^{\circ} \mathrm{W}$ \\
\hline SPAB-V-60z & Meta-riolito & 37,70 & 7,97 & 0,12777 & $-14,9$ & $-9,6$ & - & $=$ & 2,08 & $07^{\circ} 36^{\prime} 04^{\circ} \mathrm{s}$ & $38^{\circ} 02^{\circ} 30^{\prime} \mathrm{W}$ \\
\hline SPAB-FI-75 & Filito & 14,10 & $1,61$. & 0,06915 & $-43,6$ & $-33,87$ & $\therefore$ & - & 2,80 & $07^{\circ} 35^{\prime 2} 20^{\prime \prime} \mathrm{s}$ & $38^{\circ} 14^{\prime} 36^{\prime} \mathrm{W}$ \\
\hline PEAL-Di-SF & $\begin{array}{l}\text { Diatexito } \\
\text { (Sul Floresta) }\end{array}$ & 26.52 & 3,97 & 0.09057 & $-13,1$ & $-4,9$ & 1,0 & $\cdot$ & 1,33 & $08^{\circ} 39^{\prime} 00^{\prime \prime} \mathrm{s}$ & $38^{\circ} 33^{\prime} 00^{\prime} \mathrm{W}$ \\
\hline PEAL-Gp-SF & Granito Porfiro & 78,02 & 15,03 & 0,11648 & $-11,4$ & $-5,2$ & 0,6 & $-5,2$ & 1,55 & $08^{\circ} 39^{\circ} 00^{\prime \prime} \mathrm{S}$ & $38^{\circ} 33^{\circ} 00^{\circ} \mathrm{W}$ \\
\hline SPP-Mi-TAP & Migmatito & 52,70 & 10,76 & 0,1234 & $-8,6$ & $-3,0$ & 1,0 & 0,8 & 1,42 & $08^{\circ} 22^{\prime} 03^{\prime \prime} \mathrm{s}$ & $38^{\circ} 36^{\prime} 00^{\circ} \mathrm{W}$ \\
\hline SPP-Gn-REC & Augen-gnaisse & 40,41 & 8.87 & 0,1327 & $-8,9$ & $-3,9$ & 1,03 & $-0,7$ & 1,61 & $08^{\circ} 22^{\prime} 00^{\prime \prime} \mathrm{s}$ & $38^{\circ} 26^{\prime} 00^{\prime} \mathrm{W}$ \\
\hline SPP-G-10 & Granodiorito & 54,81 & 9.59 & 0,10577 & $-9,7$ & $-2,7$ & 0,75 & $-1,0$ & 1,28 & $08^{\circ} 29^{\prime} 10^{\circ} \mathrm{S}$ & $38^{\circ} 36^{\circ} 00^{\prime} \mathrm{W}$ \\
\hline SL-Gd-ABR1 & Ortognaisse & 37,84 & 8,88 & 0.14185 & $-7,8$ & $-3,6$ & $=$ & $=$ & 1,71 & $07^{\circ} 29^{\circ} 00^{-1 \mathrm{~s}}$ & $37^{\circ} 37^{\prime} 20^{\circ} \mathrm{W}$ \\
\hline SL-Gn-SOLI9 & Ortognaisse & 26,81 & 4,52 & 0,10193 & $-22,7$ & -15.5 & 0,6 & $-15,5$ & 2,14 & $07^{\circ} 36^{\prime \prime} 30^{\prime \prime} \mathrm{S}$ & $37^{\circ} 36^{\prime} 10^{\prime} \mathrm{W}$ \\
\hline SL-Gn-PO & Ortognaisse & 45,78 & 9,14 & 0.12070 & $-1[, 1$ & $-5,3$ & 1,0 & $-1,4$ & 1,59 & $07^{\circ} 18^{\prime} 10^{\circ} \mathrm{S}$ & $37^{\circ} 15^{\circ} 40^{\circ} \mathrm{W}$ \\
\hline
\end{tabular}

importante, tomado informalmente como limite norte para SPP. Como será visto, alguns destes dados já constam de publicações anteriores (como Jardim de Sá 1995, por exemplo) e outros são de dados ainda inéditos, e no seu conjunto eles são muito próximos em valores de idades daqueles do contexto do "Alto de Teixeira Terra Nova", adjacente ao norte (com o qual tem continuidade, posto que a separação aqui ensejada é meramente por razões expositivas).

Nove pontos foram computados no diagrama isocrônico (um deles não foi computado por apresentar problemas a serem revistos), fornecendo um valor de idade de $\mathrm{T}=915 \pm$ 14, Ro $=0,7120 \pm 0,0002(\mathrm{MSWD}=4,86$, dados na Tabela 4c, Fig.8). Estes valores, como será visto, são plenamente equiparáveis aqueles a serem discutidos no contexto do embasamento do "alto tectônico" adjacente ao norte. Interessante acrescentar que Jardim de Sá (1994) reportou uma determinação $\mathrm{Pb} / \mathrm{Pb}$ em monozircão nas rochas da Serra do Machado com idade de $927 \pm 25 \mathrm{Ma}$, o que reforça a validade e o significado (rochas ígneas sinorogênicas) destes valores da primeira metade do Toniano.

No mesmo diagrama foram colocados os pontos analíticos (Tabela 4d) de algumas amostras de biotita-granada gnaisses que ocorrem mais a leste da mesma faixa, nas proximidades de Coxixola-PB, e que hoje são reconhecidos como parte do metamofitos aluminosos do SPP (Grupo Sertânia e afins). Os dados de Coxixola, obtidos por Brito Neves (1975), e que então ficaram sem explicação ou entendimento possível (não se enquadrava nas ideias da época) se alinham na mesma isócrona, e talvez de forma melhor com outra razão inicial, pouco inferior a 0,712 .

ALTO TEIXEIRA-TERRA NOVA A designação deste alto é provisória, assim como a compreensão dos seu significado está no campo das hipóteses, devendo-se apenas reconhecer uma série de fases importantes (nesta borda norte do TAP, e limite com SPAB) do Paleoproterozóico (como será visto pelo registro isotópico) ao Mesozóico (evolução geomórfica da
Superfície Post-Gondwanica e Sul-Americana). Os ortognaisses desta unidade variam muito pouco em termos de composição (graníticos, monzoníticos, sienogranitos) e estruturas (augen-gnaisses, gnaisses porfiriticos fortemente laminados, forte foliação tangencial), mas cujo detalhamento geoquímico e tectônico está para ser feito ainda (há duas teses em andamento). Cerca de duas dezenas de amostras foram coletadas em diversos corpos que estão mapeados na escala 1/100.000 (Patos, Afogados, Piancó, etc. do PLGB do sistema DNPMCPRM), de Taperoá na Paraíba (pelo menos) para oeste até as imediações de Princeza Isabel-PB, incluindo localidades como Faz. Degredo, Faz. Gregório, Piedade do Ouro, Placas da Piedade, Santo Aleixo, Faz. Arroz, Agua Branca-PB, Espuma, Lagoa do Vicente, Lagoa do Guedes, Belém, Açude Francisco, Faz. Cedro, etc., facilmente discerníveis nos mapas acima comentados. Estas amostras e estes dados Rb-Sr estão expressos na Tabela 5, e os resultados obtidos sintetizados/ expostos na Fig. 9. Deve ficar claro que este cortejo de intrusivas sintectônicas (sin-Carirís Velhos) se estende muito mais para leste, mesmo fora do "alto tectônico", (que virga para norte) até o meridiano de Cabaceiras-PB (dentro do contexto do TAP), já observados no campo e mapeados, mas que não possuem ainda dados geocronológicos (estão em processo). Para oeste, a continuidade destes corpos ortognaisses é conhecida até as imediações de Serra Talhada-PE, pelo menos. É esperada uma conexão deste cortejo de ortoderivadas com aquelas bem mais a oeste, em SRP, na fronteira Pernambuco-Piaui, de forma que longitudinalmente a expressão territorial das mesmas alcance cerca de $700 \mathrm{Km}$ (entre Afeição, no Piauí e Soledade, na Paraíba). Do ponto de vista geológico, estrutural e isotópico estas amostras em nada diferem daquelas de ortognaisses mais ao sul, do TAP, e outros já discutidos. Trata-se de um contexto muito assemelhado do ponto de vista da petrografía e do aspecto estrutural, são granitóides (tipos I e tipos S) peraluminosos e metaluminosos afetados por uma importante e regional fase de tectônica 


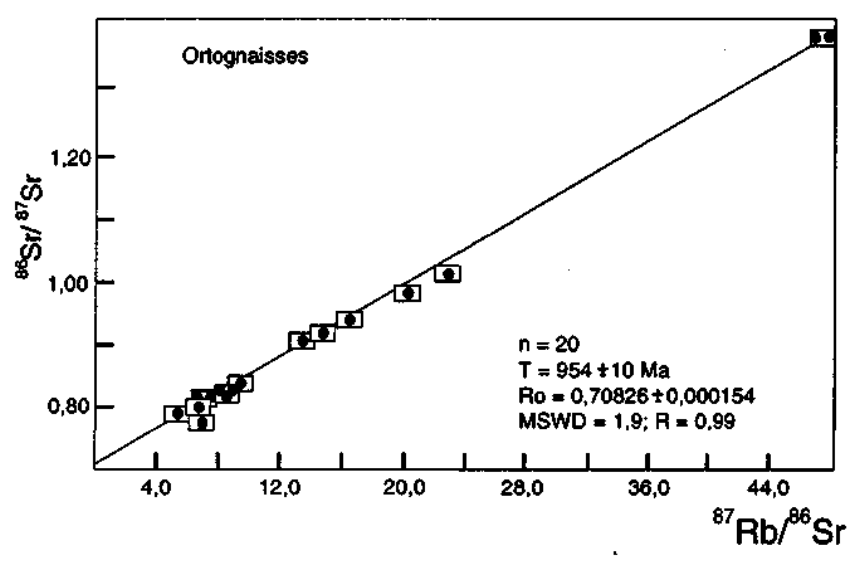

Figura 9 - Diagrama isocrônico para os ortognaisses que suportam a orografia do "Alto Teixeira-Terra Nova", entre Desterro-PB e Princesa Isabel-PB, vários diferentes corpos. Dados Tabela 5.

Figure 9 - $\mathrm{Rb} / \mathrm{Sr}$ isochronic diagram for the orthogneisses which are supporting most of the orographic features of the "Teixeira-Terra Nova tectonic high", between Princesa Izabel-PB and Desterro-PB, from different (meta) plutonic bodies, sampled at north of the Brasiliano Brejinho batholith.. Analytical data Table 5 .

tangencial. A isócrona $\mathrm{Rb}$-Sr obtida, com ótimos espalhamentos na ordenada e abcissa, indica uma idade de $\mathrm{T}=954 \pm 10$ Ma para Ro $=0,70826 \pm 0,00154(\mathrm{MSWD}=1,99$; considerada excelente pela diversidade de corpos amostrados).

A inserção ou não dos dados obtidos em corpos graníticos mais ao sul, de Carqueja a S. José do Egito (abordadas no contexto de SPP) não mudaria muito o valor da isócrona, que pela sua qualificação e representatividade é tomada como referencial básico para o fecho do metamorfísmo do Ciclo Cariris Velhos, na primeira metade do Toniano, encerrando processos de interaçào tectônica que remontam ao em torno de 1100/1150 Ma.

Idades U-Pb estão sendo presentemente conduzidas para todos estes corpos, e os primeiros resultados, ainda inéditos (imediações de Imaculada e Agua Branca na Paraíba), confirmam as assertivas acima. Idades modelo Sm-Nd, também em andamento, apontam o final do Paleoproterozóico e a primeira metade do Mesoproterozóico (entre 1,8 e 1,2 Ga) como os mais representativos valores de idades para protólitos destas rochas.

Interessante observar aqui que valores TDM mais antigos do Paleoproterozóico (como do Riaciano, tão comum no embasamento da província, em outras áreas) não são comuns nestes ortognaisses, ou só ocorrem esporadicamente, no contexto deste "alto", constiuindo-se assim um fato novo, não esperado. Em verdade, são as rochas graníticas e sieníticas neoproterozóicas, intrusivas e isotrópicas, que se alinham no "Alto Teixeira-Terra Nova" que costumam apresentar idades Tdm bem mais antigas, do Paleoproterozóico Médio (2,0 a 2,3 $\mathrm{Ga}$ ), sugerindo que nesta borda norte de SPP houve realmente uma herança (ou presença em sub-superfície) de rochas mais antigas, problema ainda não equacionado.

\section{O MACIÇO/TERRENO PERNAMBUCO-ALAGOAS} (PEAL) Caracterização Lito-Estrutural A porção do PEAL situada a oeste da Bacia de Tucano constitui um segmento crustal balizado a norte pelo Lineamento Pernambuco, com o desenvolvimento de larga zona de cisalhamento
(5 a $15 \mathrm{Km}$ ), que é compartilhada com as diversas faixas de dobramento contíguas ao norte.

Na área em foco, ao sul de SPP, este maciço é composto fundamentalmente por dois litotipos: a. Gnaisses e gnaisses migmatíticos, com alguns núcleos nebulíticos e diatexíticos, e outras variedades migmatíticas, com intercalações (relictos) frequentes de quartzitos, quartzo-xistos e anfibolitos, conjunto que foi designado (reiterando terminologia anterior) de Complexo Cabrobó, por Santos (1995).

b. Biotita-gnaisses, ortognaisses tonalíticos, leucognaisses com vestígios migmatíticos, gnaisses placosos, anfibóliognaisses, etc. e alguns fundidos anatéticos leuco-granodioríticos a leuco-monzograníticos (Complexo Belém do São Francisco, Santos 1995).

A ocorrência de uma foliação difusa de muito baixo ângulo é muito comum por todos estes complexos, indicativos de aloctonia importante. As características gerais de rochas migmatíticas, com litologias e estruturas reliquiares e de ortognaisses são predominantes e sugestivas de filiação múltipla para estas rochas

Dados Geocronológicos Nestes terrenos gnáissicomigmatíticos da parte ocidental do PEAL, em três diferentes pontos foram coletadas amostras e obtidos resultados $\mathrm{Rb}-\mathrm{Sr}$ que fortemente sugerem a continuação dos processos Cariris Velhos para o sul do SPP, a saber:

a. Cabrobó e adjacências (Brito Neves et al. 1984)

$\mathrm{n}=10, \mathrm{~T}=966 \pm 14, \mathrm{Ro}=0,7063 \pm 0,00043(\mathrm{MSWD}=6,7$, Tabela 6a, Fig. 10).

b. Norte de Belém do S. Francisco

$\mathrm{n}=6, \mathrm{~T}=1070 \pm 15, \mathrm{Ro}=0,7041 \pm 0,00025(\mathrm{MSWD}=4,12$,

Tabela 6b, Fig. 11).

c. Sul de Floresta-PE

$\mathrm{n}=4, \mathrm{~T}=1136 \pm 27, \mathrm{Ro}=0,70563 \pm 0,00046(\mathrm{MSWD}=13,6$,

Tabela 6c, Fig. 12)

Estes valores guardam certa coerência entre si e são significativos pela escala regional de abordagem, devendo aqui ser

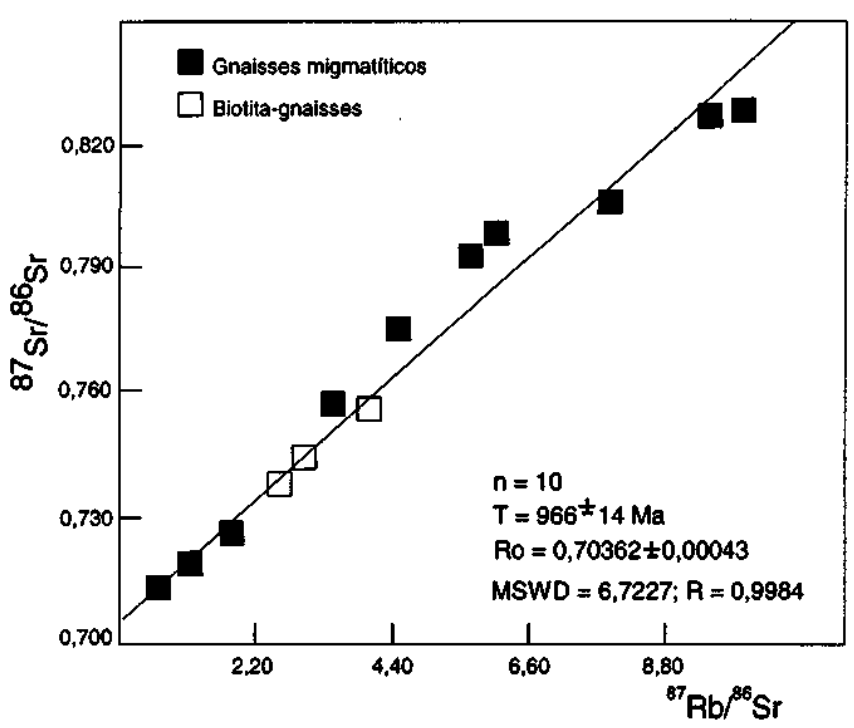

Figura 10 - Diagrama isocrônico para os gnaisses migmatíticos de área ao norte de Cabrobó-PE, na parte mais ocidental do Maciço Pernambuco-Alagoas. Dados Tabela 6 . Figure $10-\mathrm{Rb} / \mathrm{Sr}$ isochronic diagram for the migmatitic gneisses of the westernmost portion of the PEAL massif, área north of Cabrobó-PE. Analytical data Table 6a. 


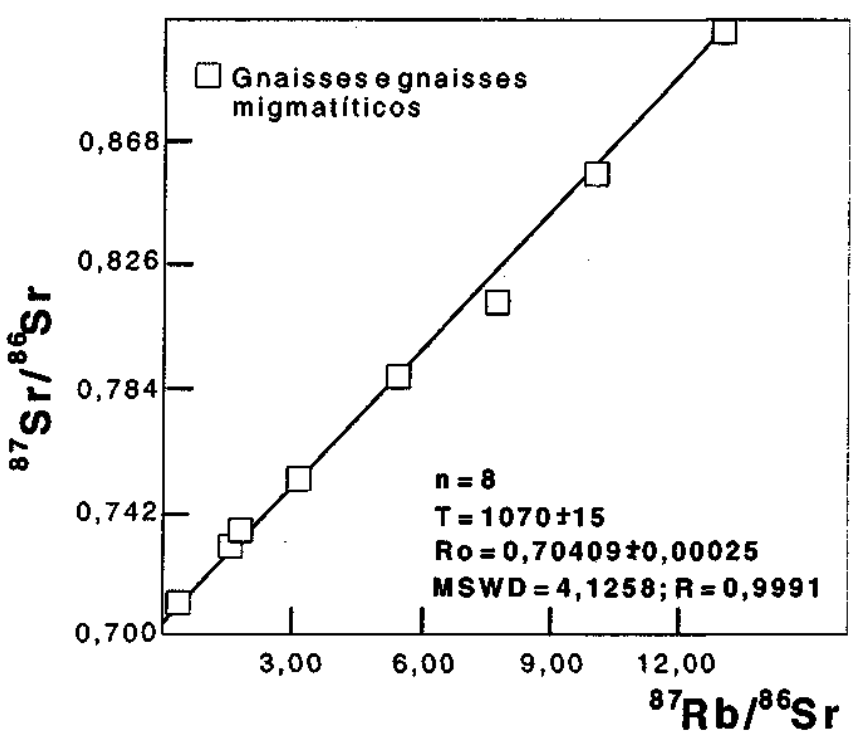

Figura 11 - Diagrama isocrônico para os gnaisses migmatíticos da área ao norte de Belém do S. Francisco, na parte ocidental do Maciço Pernambuco-Alagoas. Dados Tabela $6 b$. Figure $11-\mathrm{Rb} / \mathrm{Sr}$ isochronic diagram for the migmatitic gneisses of the westernmost portion of the PEAL massif, área north of Belém do São Francisco-PE. Analytical data Table 6b.

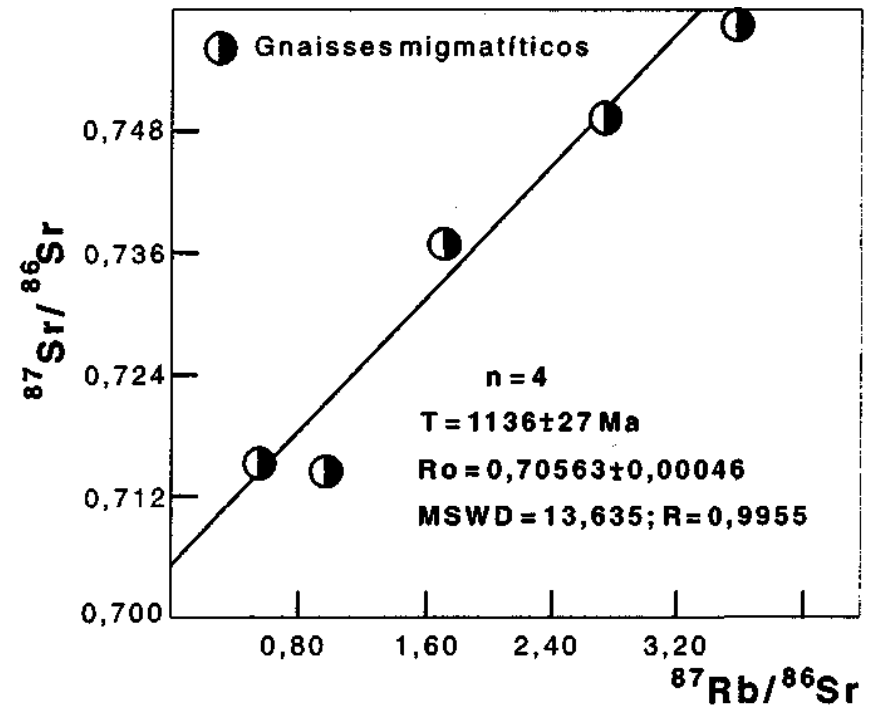

Figura 12 - Diagrama isocrônico para os gnaisses migmatiticos (diatexíticos) da área ao sul de Floresta-PE, na parte ocidental do Maciço Pernambuco-Alagoas. Dados Tabela 6c. Figure $12-\mathrm{Rb} / \mathrm{Sr}$ isochronic diagram for the migmatitic gneisses (diatexites) of the área south of Floresta-PE, western part of the PEAL massif. Analytical data Table $6 c$.

reiterado que eles reproduzem eventos já denotados nos sistemas de dobramentos (SPAB e SPP = Zona Transversal) postados imediatamente ao norte do maciço, após o Lineamento Pernambuco. Falta a confirmação de valores nesta ordem pelo método U-Pb, no maciço, e esforços neste sentido estão em fase de progresso.

Apenas dois resultados Sm-Nd foram obtidos até agora em rochas deste contexto, sendo de um diatexito $-\mathrm{Tdm}=1,33-\mathrm{e}$ de um granito porfirítico intrusivo $-\mathrm{Tdm}=1,55-$, que enfatizam idade mesoproterozóica para os protólitos (Tabela 8). Vários outros resultados estão em andamento, muitos são ainda de uma tese inédita (Kei Sato, informação verbal), todos eles indicando idades mesoproterozóicas para os protólitos, e ajustados de certa forma ao quadro regional aqui comentado. Deve ser destacado que no extremo oeste do maciço foi identificado um pequeno núcleo do Mesoarqueano (área de Riacho Seco), que já figura no mapa geocronológico da Bahia de 1987. É possível preconizar que o predomínio dos materiais deste maciço seja Mesoproterozóico Superior, com eventuais núcleos mais antigos (paleoproterozóicos ou "transamazônicos" e arqueanos, como Riacho Seco), tanto na Bahia como no lado oriental, em Pernambuco e Alagoas, de acordo com dados de reconhecimento $\mathrm{Rb}-\mathrm{Sr}$, muitos deles inéditos. Por todo o maciço, nas suas partes oeste e leste (nesta, de forma mais acentuada), as ativações tectono-metamórfica e granitogênica (regeneração de fato) no Brasiliano foram muito significativas.

\section{CONCLUSÕES, PERPECTIVAS E IMPLICAÇÕES}

A caraterização de um processo orogenético está bem consignado por toda zona transversal da Província Borborema, com provável desenvolvimento até a parte norte do SRP e parte ocidental do PEAL. Esta assertiva, auferida no estágio preliminar de estudos, implica em reconhecer processos de divergência, com desenvolvimento de sítios tafrogênicos e suas litologias típicas, e localmente de assoalho oceânico, no Mesoproterorozóico (entre 1100-1150 Ma), seguido de subducção e desenvolvimento de diferentes arcos magmáticòs (ao redor de 1030-980 Ma), não sincrônicos e associados lateralmente (Pajeú, Alto Moxotó, Agua Branca, etc.), seguidos de um processo colisional amplo de caráter regional, em parte precoce (já no final do Mesoproterozóico), em parte alcançando a primeira metade do período Toniano (entre 950 e 1000 Ma).

Estes eventos são compatíveis com um ciclo completo de Tectônica Global, dito wilsoniano, nesta porção da província ao sul do Lineamento de Patos, com continuidade lateral e longitudinal a ser perquirida (no PEAL, SRP e na contraparte africana). Cabe destacar também que não foi encontrada registros expressivos deste ciclo nos domínios setentrionais da Província, ao norte do Lineamento Patos, mas há alguns indícios.

Da mesma forma que estes dados preliminares permitem adiantar estas afirmações, é preciso reconhecer a demanda (em número e amplitude) dos estudos geológicos gerais (geoquímica, petrologia, estruturais) e isotópicos para o equacionamento dos problemas levantados. Esta demanda é reconhecida, e o prosseguimento dos trabalhos é meta já em operação, principalmente com a utilização do desenvolvimento de teses de doutoramento, por alunos do IGc-USP, IGc-UNESP e da Universidade do Kansas, em Lawrence (USA).

Estes processos de interação de placas, na passagem do Mesoproterozóico para o Neoproterozóico, estão bem marcados no nosso continente, na Província Tapajós, porção sul-ocidental do Cráton Amazônico, consoante a orogenia Sunsás-Aguapeí, sintetizada por Litherland et al. (1985). Há vários argumentos e indicações de muitos trabalhos recentes da extensão de processos orogênicos coevos no embasamento dos Andes (Faixa "Garzon-Santa Marta", de Kroonenberg (1982) e o "Terreno Occidentalia" de Dália Salda et al. (1994), entre outros), da Venezuela ao sul do Chile. Todos estes com conhecimento muito preliminar, caráter pouco aprofundado dos dados (por razões óbvias dos muitos retrabalhamentos sobrepostos). 
Estes processos orogênicos do embasamento dos Andes, por sua vez, têm sido o alicerce (entre outros dados) para as indicações de que Laurentia e Gondwana estiveram conectados ou muito próximos, somente havendo a separação definitiva depois da Orogênese Famatiniana, no alvorecer do Paleozóico. Ou seja, há forte tendência de se reconhecer a Colagem Grenville na parte ocidental do continente, com extensão ao território brasileiro.

Considerando a importância da Colagem Grenville, de nível e expressão mundial, responsável que foi pela edificação do Supercontinente Rodínia, é claro que estes dados da Orogenia Carirís Velhos passam a ter significado especial, digno de nota, de muita expectativa científica justificada, requerendo amplos investimentos na escala de conhecimento. Sem favor, esta é a mais concreta evidência de orogenia correlacionável a parte final do Grenville (Orogenia Ottawan) no nosso continente (de fato, em todo Gondwana), por diferentes métodos de abordagem, e este fato vai ter ampla repercussão e despertar diferentes interesses de pesquisa. Este é um fato novo e significativo que transcende os interesses científicos de nsso país. Principalmente tendo em vista que esta identificação é nos domínios de uma província dita brasiliana (e que é brasiliana, de fato), e a ampla participação de províncias brasilianas na articulação de Gondwana.

A identificação e proposição do Ciclo Cariris Velhos devem ser compreendidas sem excluir o reconhecimento claro de sobreposição dos eventos extensionais, vulcano-sedimentares, magmáticos, deformacionais, etc. do Neoproterozóico, pós-950 Ma. Ou seja, a constatação é de policiclismo das faixas móveis da Borborema, sobre um embasamento predominantemente paleoproterozóico (consubstanciado no Ciclo Transamazônico), muito bem conhecido nos núcleos cratônicos e no substrato de vários maciços. As orogenias no Mesoproterozóico (como Cariris Velhos) - relativamente de menor expressão territorial que as paleoproterozóicas - e no Neoproterozóico (há fortes indícios de eventos orogênicos em torno de $730 \mathrm{Ma}$ e $600 \mathrm{Ma}$ ) são as responsáveis pelo policiclismo mencionado.

A estruturação final da província, com seu leque de estruturas chegando diagonalmente à linha de costa é uma consequência do movimento direcional de seus "shear belts", provavelmente num processo de extrusão (escape tectonics) tardio (540-520 Ma), segundo alguns dados isotópicos, e bem posterior a última orogênese (acrescionária, ca. $600 \mathrm{Ma}$ ), que atingiu a região no fecho da Colagem Brasiliano/PanAfricana. Os processos lineagênicos que deram a última forma geográfico-geológica pré-drift à província, chegaram a segunda metade do período Cambriano (Figueiredo 1992, Neves 1996).

Nestes termos, a própria definição das orogenias do Brasiliano e o Brasiliano como ciclo apresentam problemas e novas considerações a serem discutidos, sendo preliminarmente encarados como uma colagem reponsável pela articulação do supercontinente Gondwana Ocidental. Os passos de toda a história tectogenética do Neoproterozóico pós-950 Ma estão ainda em aberto, para ser equacionados, contando com pesquisas nos lados brasileiro e africano.

\section{REFERÊNCIAS}

ANGELIM, L. A. A. 1988.Programa Levantamentos Geológicos Básicos do Brasil , Carta metalogenética/previsional - Escala J/100 000 (Folha SC.24-V-A-III Santa Filomena).Brasilia, DNPM/CPRM. 146 p.

BRITO NEVES, B. B. 1975. Regionalização Tectônica do Precambríano Nordestino. 198 p. São Paulo-SP (Tese de doutoramento, Instituto de Geociências, Universidade de S. Paulo)

BRITO NEVES, B. B. 1981. O Ciclo Brasiliano no Nordeste. In : SIMP. GEOL. NORDESTE, 10. Recife, 1981. Atas... Recife, SBG/Núcleo Nordeste, p.329-336.

BRITO NEVES, B. B.; VANDOROS, P. ; PESSOA, D. A. R : CORDANI, U.G. 1974. Reavaliação dos dados geocronológicos do Pré-Cambriano Brasileiro.. In: CONGR. BRAS. GEOL., 28, Porto Alegre, 1974. Anais... Salvador, SBG, v.6, p.261-271.

BRITO NEVES, B.B.; PESSOA, D.A.R.: PESSOA, R. J. R.: KAWASHITA, K.; CORTES, P.L. 1984 Estudo Geocronológico das rochas do embasamento da quadrícula de Salgueiro-PE. In: CONG. BRAS. GEOL., 33. Rio de Janeiro,1984. Anais... Rio de Janeiro, SBG, v.5, p.2473-2489.

BRITO NEVES, B. B.: VAN SCHMUS, W. R.; BASEI, M. A. S. 1990a. Contribuição ao estudo da evolução geocronológica do Sistema de Dobramentos Piancó-Alto Erigida. In: CONG. BRAS. GEOL., 36. Natal-RN, 1990. Anais... Natal, SBG, v.5, p. 2697-2710.

BRITO NEVES, B. B.; TEIXEIRA, W.; TASSINARI, C. C. G.; KAWASHITA, K. 1990b. A contribution to the subdivision of the Precambrian in south America. Rev. BRAS. Geociências. 20 (1/4): 267276

BRITO NEVES, B. B.; VAN SCHMUS, W. R. ; HACKSPACHER, P. C.; SANTOS, E. J. 1995 Geocronologia da Borborema, 1995 : Os fatos e as questões abertas. In : SIMP. GEOL. NORDESTE, 16. Recife, 1995. Afav....Recife, SBG, Núcleo Nordeste (Boi. 14, V.2), p.410-413.

CAMPOS NETO, M.C.; BITTAR, S.M.B.; BRITO NEVES, B. B. 1994. Domínio Tectônico Rio Pajeú - Província Borborema: Orogêneses superpostas no Ciclo Brasiliano/Pan-Africano. In: CONG. BRAS GEOL., 38. Balneário Camboriú,1994. Boletim de Resumos Expandidos.... Balneário Camboriú, SBG, v.1, p.221-222.
CONDIE, K. C. 1989. Plate Tectonics and crustal evolution. 3 ed., Oxford, Pergamon Press, $476 \mathrm{p}$./

DALLA SALDA, L.; VARELA, R.; CINGOLANI.C. 1994. Sobre lacolision de Laurentia-Sudamerica y el Orogeno Famatiniano. In: CONG. GEOL. ARGENTINO, 12 y CONG. EXPLOR. HIDROCARB, 2. Mendonza, 1994. Actas... Mendonza. t. III, p.358-386.

FIGUEIREDO, L. L. 1992 Etude petrostructurale et geochronologique Ar ${ }^{40}$, $A r^{39}$ de systemes decrochants ductiles: Léxemple de Ia Province Borborema (NE - Brésil). 31p. Villlefranche-sur-Mer, Paris (Université Pierrre et Marie Curie- Paris VI, Memoire, Institute de Géodynamique).

JACOBS, J.; THOMAS, R. J. 1994. Oblique collision at about $1.1 \mathrm{Ga}$ along the southern margin of the Kaapvaal continent, south-east África. Geol. Rundsch. (1994): 83: 322-33.

JACOBS, J.; THOMAS, R. J.; WEBER, K. 1993. Accretion and indentation tectonics at the southern edge of the Kaapvaal craton during Kibaran (Grenville) orogeny. Geology: 21:203-206

JARDIM DE SÁ, E. F. 1994. A faixa Seridó (Província Borborema, Nordeste do Brasil) e o seu significado geodinâmica na Cadeia Brasiliano/Pan Africana, 804 p. Brasília-DF (Tese de doutorado, n.3, Instituto de Geociências-Universidade de Brasília).

JARDIM DE SÁ, E. F. 1995. A faixa Seridó (Província Borborema, NE do Brasil) e o seu significado geodinâmico na Cadeia Brasiiano/Pan-AMcana. In: SIMP. GEOL. NORDESTE, 16. Recife, 1995.Atas... Recife, SBG, Núcleo Nordeste (Boi. 14, v.2). p.394-398.

JARDIM DE SÁ, E. F.; MACEDO, M. H.F.; FUCK, R. A.; KAWASHITA, K.; PEUCAT, J. J.; SOUZA, Z.S.; LETERRIER, J. 1995. Granitóides sinorogênicos ca. 1,0 Ga na Província Borborema, NE do Brasil. In : SIMP. GEOL. NORDESTE, 16. Recife, 1995. Atas... Recife, SBG, Núcleo Nordeste (Boi. 14, v. 1). p.162-165.

KROONENBERG, S. B. 1982. A grenvillian granulite belt in the Colombian Andes and its relation to the Guiana Shield. Geologie en Mijnbow, 61: 325-333.

LIMA, M.I.C.; GAVA, A.; FERNANDES, P. E. C. A.; PIRES, J.L.; SIGA Jr., O.; ORTIZ, L.R.C. 1986. Geologia e Recursos Minerais da Região de Floresta-PE. In: SIMP. GEOL. NORDESTE, 12. João Pessoa,1986. Atas... João Pessoa, SBG/Núcleo Nordeste, p. 290-303. 
LIMA, E. S.; BITTAR, S. M.B.; ACCIOLY, A. C. A.; VANNUCI, R.; MAZZUCHELLI, M. 1996. Caracterização petrogenética das rochas meta-vulcânicas da Faixa Piancó-Alto Brígida (Folha Serra Talhada), NE Brasileiro.In: CONG. BRAS. GEOL. 39. Salvador-BA, 1996. Salvador, SBG/Núcleo da Bahia (em impressão).

LITHERLAND, M.; KLINCK, B. A.; O'CONNOR, E. A.; PITFIELD, P.E. J. 1985. andean -trending mobile belts in the Brazilian Shield. Nature, 314: 345-348.

MASCARENHAS, J. F.; GARCIA, T. W. 1987. Mapa geocronológico do Estado da Bahia; texto explicativo. Salvador-BA, Superintendência de Geologia e Recursos Minerais (BA). 186 p.

MOORBATH, S. 1975. Geological interpratation of whole-rock isochron dates from high grade gneiss terrains. Nature, 255: 391.

NEVES, S. P. 1996. Étude dês relations entre magmatisme et zones de cisaillement lithspheriques: exemple dês décrochements de Pernambuco et Fazenda Nova -État de Pernambuco- BrésiL, 243 p., Montpellier-France (These Doctorat - Université de Montpellier II Sciences et Tecniques du Languedoc

SANTOS, E. J. 1995. O complexo granítico de Lagoa das Pedras: acresção e colisão na região de Floresta (Pernambuco), Província Borborema. S. Paulo-SP, 220p.(Tese de doutoramento, Instituto de Geociências da Universidade de São Paulo).

SANTOS, E. J.; BRITO NEVES, B. B.; VAN SCHMUS, W. R. 1995. O complexo granítico Lagoa das Pedras: Acresçao e colisão na região de Floresta (Pernambuco), Província Borborema. In: SIMP. GEOL. NORDESTE.16. Recife, 1995. Atas...Recife, SBG, Núcleo Nordeste (Boi. 14,v. 2). p.401-406.

SANTOS, E. J; BRITO NEVES, B. B. 1984. Província Borborema. In: ALMEIDA, F. F. M. \& HASUI, Y. (coords.) o Pré-Cambriano do Brasil São Paulo, Edgard Blücher. p. 123-186.

SCHEID, C.; FERREIRA, C. A. 1991. Programa Levantamentos Geológicos Básicos do Brasil: carta geológica, carta metalogenético-previsional Escala 1:100.000 (follia SB.24-Z-D-I-Patos),. Estados de Pernambuco e da Paraíba.. Brasília, DNPM/CPRM. 148 p.
SIAL, A. N.; BRITO NEVES, B. B.; BEURLEN, H.; MELO, P.G.M.; PESSOA, R. J. R. P. 1983. Projeto Extremo Oeste de Pernambuco (Quadrícula de Salgueiro e parte de Chorrochó e Pamamirim - PE.. Relatório Final. Recife-PE, Centro de Tecnologia da UFPE, Departamento de Geologia, 51 p. (Relatório Final, Convénio DNPM 40. Distrito/ C.T. UFPE).

SIAL, A. N.; FERREIRA, V. P.; JARDIM DE SÁ, E. F.; SANTOS, E.J.; MEDEIROS, V. C.; AMARO, V.E. 1996. The plutonic map sheet Northeast Brazil; Beoproterozoic to Phanerozoic granitoids of the Borborema Province. In : CONG. BRAS. GEOL, 39, Salvador-BA, 1996. Anais...Salvador, SBG/Núcleo da Bahia, v. 6: 325-329.

SILVA FILHO, M. A.; NESI, J.; MENDES, V.A. 1985. Projeto Cachoeirinha. Recife-PE, Convénio CPRM/DNPM, v. 1.128 p.

VAN SCHMUS, W. R.; BRITO NEVES, B. B.; HACKSPACHER, P. C. BABINSKI, M. 1995a. U/Pb and $\mathrm{Sm} / \mathrm{Nd}$ geochronologic studies of the eastern Borborema Province, Northeast Brazil: initial conclusions. Journal of South American Earth Sciences, 8 (3/4): 267-288.

VAN SCHMUS, W. R.; BRITO NEVES, B. B.; HACKSPACHER, P. C.; BABINSKI, M.; FETTER, A.; DANTAS, E. 1995b. Neoproterozoic and Late Mesoproterozoic sedimentary and volcanic sequences in the Borborema Province. In: SIMP. GEOL. NORDESTE, 16. Atas... Recife-PE, SBG/Núcleo Nordeste (Boi. 14, v. 2). p.391-393.

VEIGA JR. J. P.; FERREIRA, C. A. 1990. Programa Levantamentos Geológicos Básicos do Brasil: carta geológica, carta metalogenético/ previsional - Escala 1:1000.000 (folha SB.24-Z-C-VI Afogados de Ingazeira) Estados de Pernambuco e Paraíba Brasília, DNPM/CPRM $121 \mathrm{p.}$.

WANDERLEY, A. A. 1990. Programa levantamentos Geológicos Básicos do Brasil: carta geológica, carta metalogenético/previsional - Escala 1: 1000.000 (folha SB.24-Z-D-IVMonteiro) Estados de Pernambuco e Paraiba. Brasília, DNPM/CPRM. 100 p.

MANUSCRITO No 866

Recebido em 31 de agosto de 1996 Revisão dos autores em 30 de novembro de 1996 Revisão aceita em 15 de janeiro de 1997 